\title{
Rapid phosphatidic acid accumulation in response to low temperature stress in Arabidopsis is generated through diacylglycerol kinase
}

\author{
Steven A. Arisz ${ }^{1}$, Ringo van Wijk ${ }^{1}$, Wendy Roels ${ }^{1}$, Jian-Kang Zhu ${ }^{2,3}$, Michel A. Haring ${ }^{1}$ and \\ Teun Munnik ${ }^{1 *}$ \\ ' Department of Plant Physiology, Swammerdam Institute for Life Sciences, University of Amsterdam, Amsterdam, Netherlands \\ ${ }^{2}$ Department of Horticulture and Landscape Architecture, Purdue University, West Lafayette, IN, USA \\ ${ }^{3}$ Shanghai Center for Plant Stress Biology and Shanghai Institute of Plant Physiology and Ecology, Shanghai Institutes of Biological Sciences, Chinese Academy of \\ Sciences, Shanghai, China
}

\section{Edited by:}

Xuemin Wang, University of

Missouri-St. Louis, USA

Reviewed by:

Uener Kolukisaoglu, University of

Tuebingen, Germany

Ying Gu, Pennsy/vania State

*Correspondence:

Teun Munnik, Department of Plant

Physiology, Swammerdam Institute

for Life Sciences, University of

Amsterdam, Science Park 904,

NL-1098 XH Amsterdam,

Netherlands.

e-mail: t.munnik@uva.nl
University, USA

Phosphatidic acid ( $\mathrm{PtdOH})$ is emerging as an important signaling lipid in abiotic stress responses in plants. The effect of cold stress was monitored using ${ }^{32}$ P-labeled seedlings and leaf discs of Arabidopsis thaliana. Low, non-freezing temperatures were found to trigger a very rapid ${ }^{32} \mathrm{P}-\mathrm{PtdOH}$ increase, peaking within 2 and $5 \mathrm{~min}$, respectively. In principle, $\mathrm{PtdOH}$ can be generated through three different pathways, i.e., (1) via de novo phospholipid biosynthesis (through acylation of lyso-PtdOH), (2) via phospholipase $D$ hydrolysis of structural phospholipids, or (3) via phosphorylation of diacylglycerol (DAG) by DAG kinase (DGK). Using a differential ${ }^{32}$ P-labeling protocol and a PLD-transphosphatidylation assay, evidence is provided that the rapid ${ }^{32} \mathrm{P}-\mathrm{PtdOH}$ response was primarily generated through DGK. A simultaneous decrease in the levels of ${ }^{32} \mathrm{P}-\mathrm{Ptd}$ InsP, correlating in time, temperature dependency, and magnitude with the increase in ${ }^{32} \mathrm{P}-\mathrm{PtdOH}$, suggested that a PtdlnsP-hydrolyzing PLC generated the DAG in this reaction. Testing T-DNA insertion lines available for the seven DGK genes, revealed no clear changes in ${ }^{32} \mathrm{P}-\mathrm{PtdOH}$ responses, suggesting functional redundancy. Similarly, known cold-stress mutants were analyzed to investigate whether the PtdOH response acted downstream of the respective gene products. The hos 1, los 1, and fry 1 mutants were found to exhibit normal PtdOH responses. Slight changes were found for ice1, snow1, and the overexpression line Super-ICE1, however, this was not cold-specific and likely due to pleiotropic effects. A tentative model illustrating direct cold effects on phospholipid metabolism is presented.

Keywords: abiotic stress, cold stress, diacylglycerol kinase, lipid signaling, phosphatidic acid, phosphoinositide, phospholipase, plant signaling

\section{INTRODUCTION}

The potential to survive low temperatures is one of the factors that determine the geographical distribution of plants. Moreover, freezing and cold stress restrict the arable land and yield of crops. Therefore, much effort is made to understand the mechanisms that make plants more tolerant to low temperatures. One of the most popular plant models in these studies is Arabidopsis thaliana (Van Buskirk and Thomashow, 2006).

Like many temperate plants, Arabidopsis is capable of cold acclimation, i.e., during a period of cold, non-freezing temperatures, its tolerance for freezing temperatures increases. This process, also referred to as cold hardening, involves a myriad of metabolic and developmental changes, accompanied by accumulation of proteins and compatible solutes, and alterations in membrane composition (Uemura et al., 1995; Thomashow, 1999; Cook et al., 2004; Chinnusamy et al., 2007).

Transcriptome profiling and mutant screens have resulted in the characterization of multiple genes involved in the initiation of cold acclimation and freezing tolerance. These include the conserved CBF/DREB1 transcription factors that are responsible for activating the expression of many cold response (COR) genes via conserved C-repeat elements in their promoters. Zhu and coworkers have used Arabidopsis plants transfected with the RD29A-LUC construct to select for mutants with altered responses to cold treatment ("cold response mutants"), resulting in the identification of several genes. Enhanced cold-induced expression was found in the fryl (Xiong et al., 2001) and hos 1 (Ishitani et al., 1998) mutants, whereas los1 (Guo et al., 2002) showed decreased expression. Moreover, the dominant negative ice1 (Chinnusamy et al., 2003) mutation has been demonstrated to negatively affect cold-induced gene transcription by interfering with the function of AtICE1, a myc-type transcription factor which functions in CBF transcription in cold signaling. The $m y b$-type transcription factor SNOW1/MYB15, also binds to the CBF promoter region, interacting with ICE1 (Agarwal et al., 2006). Upon exposure to cold stress $\left(4^{\circ} \mathrm{C}\right)$, the transcript levels of CBF/DREB1 genes increase within 15-30 min, followed by the accumulation of COR gene transcripts after about $2 \mathrm{~h}$ (Thomashow, 1999). 
Much less is known about the signal transduction pathway that preceeds the gene expression changes. Nonetheless, there is mounting evidence that $\mathrm{Ca}^{2+}$ functions as a second messenger (Knight et al., 1996; Knight and Knight, 2000; Carpaneto et al., 2007) and that part of the pathway involves activation of a MAP kinase cascade (Jonak et al., 1996; Mizoguchi et al., 1996; Teige et al., 2004). One of the latest additions to the field of cold signaling is the formation of the lipid second messenger, phosphatidic acid (PtdOH). In suspension-cultured cells, this phospholipid was shown to accumulate within minutes of cold stress (Gawer et al., 1999; Ruelland et al., 2002; Cantrel et al., 2011). Like $\mathrm{Ca}^{2+}$ and MAP kinases, PtdOH is involved in the signal transduction pathways of several other plant stress responses, including drought, wounding, and pathogen infection (Li et al., 2009; Testerink and Munnik, 2011), and it is not unlikely that these pathways strongly overlap.

In stress-induced signal transduction, $\mathrm{PtdOH}$ responses have been mainly attributed to two pathways. It is the direct product of phospholipase D (PLD), which hydrolyses structural phosholipids like phosphatidylcholine (PtdCho) and phosphatidylethanolamine (PtdEtn), and a secondary product of the phospholipase C (PLC) pathway, which first hydrolyzes polyphosphoinositides (PPIs) to diacylglycerol (DAG), that is subsequently phosphorylated to PtdOH by diacylglycerol kinase (DGK). However, metabolism of DAG and PtdOH is more complex, since multiple sources have now been demonstrated, and $\mathrm{PtdOH}$ is formed de novo via acylation of glycerolphosphate (Gro3P) as a common intermediate in glycerolipid biosynthesis, both in the plastid and the ER. Thus, PtdOH is precursor to all phosphoglycerolipids as well as triacylglycerols and galactolipids, and its turnover is crucial in determining lipid metabolic fluxes and membrane compositions.

The Arabidopsis genome is predicted to encode 12 PLDs, 9 PLCs, and 7 DGKs (Gomez-Merino et al., 2004; Testerink and Munnik, 2005, 2011; Tasma et al., 2008; Arisz et al., 2009; Li et al., 2009; Munnik and Testerink, 2009). Their genetic abundance and specific gene expression patterns suggests that some of these enzymes are specific to certain locations in specific organs and/or involved in distinct processes. The PLC/DGK and PLD pathways have been implicated in the transcriptional induction of an array of cold-induced genes in Arabidopsis (Vergnolle et al., 2005). PLD $\delta$ has been shown to be important in the generation of freezing tolerance during acclimation (Li et al., 2004) in contrast to PLD $\alpha 1$ which negatively influenced survival of freezing, both in cold-acclimated and in non-acclimated plants (Rajashekar et al., 2006; Chen et al., 2008; Du et al., 2010). In suspension-cultured cells, biochemical evidence was found that cold shock activated both PLC/DGK and PLD pathways (Ruelland et al., 2002). Moreover, several genes have been shown to be upregulated in response to cold stress, including $P L D \alpha 1, P L D \delta$, PLC1, PLC4, PLC5, DGK1, and DGK2 (Hirayama et al., 1995; Gomez-Merino et al., 2004; Li et al., 2004; Lee et al., 2005). Also, in maize roots and leaves several genes encoding DGK, PLC, and PLD were upregulated within $30 \mathrm{~min}$ of cold stress (Sui et al., 2008).

In this study we show that Arabidopsis seedlings and leaf disks exposed to low temperatures accumulate $\mathrm{PtdOH}$ within minutes.
Using a differential ${ }^{32}$ P-labeling strategy (Munnik et al., 1998b; Arisz et al., 2009) and PLD's ability to transphosphatidylate nbutanol to PtdBut (Munnik et al., 1995, 1998b), we provide evidence that the rapid $\mathrm{PtdOH}$ response does not originate from PLD but from DGK. The simultaneous decrease in the level of phosphatidylinositolphosphate (PtdInsP) suggests the involvement of a PtdInsP-hydrolyzing PLC. T-DNA insertion lines were used to address the question which DGK and PLC were involved, while the COR mutants hos 1, los 1, fry 1, ice1, and snow1 were analyzed to see whether PtdOH acts up- or down-stream of these genes in the COR.

\section{MATERIALS AND METHODS PLANT MATERIAL}

A. thaliana seeds were sterilized in $70 \% \mathrm{EtOH}(1 \mathrm{~min})$ and $25 \%$ bleach $(20 \mathrm{~min})$, and sown on media in Petri dishes. For ${ }^{32} \mathrm{P}$-radiolabeling experiments, seedlings were grown on $1 / 2 \mathrm{x}$ Murashige and Skoog (MS) basal medium at $\mathrm{pH} 5.7(\mathrm{KOH})$, solidified with $1.0 \%$ bacto-agar. The ice1, snow1, los 1, hos1, fry1 mutants, and their WT's were grown on $1 \mathrm{x}$ MS medium supplemented with $1 \%$ sucrose. A $16 \mathrm{~h}$ light $/ 8 \mathrm{~h}$ dark regime (150 umol quanta $\mathrm{m}^{-2} \mathrm{~s}^{-1}$ ) at $21^{\circ} \mathrm{C}$ was set. To promote uniform germination, plates were kept in the dark at $4^{\circ} \mathrm{C}$ for 2 days before transfer to a climate room.

\section{RT-PCR EXPRESSION ANALYSES OF DGK T-DNA INSERTION LINES}

Homozygous T-DNA insertion lines of the DGK genes where genotyped using primer sequences found in Table A1 (Figure A3). Wild type A. thaliana Col-0 or lines containing TDNA insertions in DGK1, -3, -5, -7 genes were grown on $1 / 2 \mathrm{x}$ Murashige and Skoog (MS) basal medium supplemented with $1 \% \mathrm{w} / \mathrm{v}$ sucrose at $\mathrm{pH} 4.6$, solidified with $1 \% \mathrm{w} / \mathrm{v}$ daishin agar. To promote uniform germination, plates were kept in the dark at $4^{\circ} \mathrm{C}$ for 2 days before transfer to a climate room. Seedlings where harvested for RNA isolation after 9 days in a climate room with light regime set at $16 \mathrm{~h}$ light $/ 8 \mathrm{~h}$ dark at $21^{\circ} \mathrm{C}$ and Relative Humidity $70 \%$. Additionally, flowers of $A$. thaliana lines containing T-DNA insertions in DGK2, -4, -6 genes, and wild type Col-0 were collected from plants grown in a greenhouse under the same environmental conditions. RNA was isolated using Tri Reagens LS (Sigma) and treated with Turbo RNAse free DNAse (Ambion) for removal of genomic DNA. The RNA concentration and integrity was analyzed using a Nanodrop ND-1000 spectrophotometer.

cDNA was synthesized from $2 \mu$ g total RNA using RevertAid $\mathrm{H}$ Minus Reverse Transcriptase (Fermentas) according to the manufacturers protocol. RT-PCR was performed using Accuprime Taq DNA polymerase (Invitrogen). Table A2 contains the primer sequences used to amplify the different Arabidopsis DGK genes and the At2g28390 (SAND family) reference gene (Figure A4; Hong et al., 2010). Thermal cycling was done according to the following profile; $94^{\circ} \mathrm{C}$ for $2 \mathrm{~min}$, followed by 40 cycles of $94^{\circ} \mathrm{C}$ for $30 \mathrm{~s}, 50^{\circ} \mathrm{C}$ for $30 \mathrm{~s}, 68^{\circ} \mathrm{C}$ for $2 \mathrm{~min}$ and 1 cycle of $68^{\circ} \mathrm{C}$ for $6 \mathrm{~min}$.

\section{${ }^{32} \mathrm{P}$-ORTHOPHOSPHATE RADIOLABELING in vivo AND ANALYSIS OF PHOSPHOLIPIDS}

Five-days-old seedlings or leaf disks $(5 \mathrm{~mm} \emptyset)$ of 3-weeks-old plants were transferred to a $2.0 \mathrm{ml}$ Eppendorf tube, containing 
MES (2-[N-morpholino]ethane sulfonic acid)-based buffer of $2.56 \mathrm{mM}$ MES ( $\mathrm{pH}$ 5.7) and $1 \mathrm{mM} \mathrm{KCl}$. To label phospholipids, $10 \mu \mathrm{Ci}$ carrier-free ${ }^{32} \mathrm{P}$-orthophosphate per tube was added for $16 \mathrm{~h}$, unless indicated otherwise. Cold shock treatments were executed by transferring tubes to ice water. Incubations were stopped by the addition of $\mathrm{HClO}_{4}$ (final concentration 5\%, w/v), and 10 min of subsequent shaking.

The total solvent was removed and $375 \mu \mathrm{l} \mathrm{CHCl} 3 / \mathrm{MeOH} / \mathrm{HCl}$ (50:100:1, by vol.) was added to extract the lipids. After $10 \mathrm{~min}$ of vigourous shaking, two phases were induced by adding $375 \mu \mathrm{l}$ $\mathrm{CHCl}_{3}$ and $200 \mu \mathrm{l} 0.9 \%(\mathrm{w} / \mathrm{v}) \mathrm{NaCl}$. The organic lower phase was then transferred to a tube containing $375 \mu \mathrm{l} \mathrm{CHCl}_{3} / \mathrm{MeOH} / 1 \mathrm{M}$ $\mathrm{HCl}$ (3:48:47, by vol.). Shaking, spinning, and removing the upper phase yielded a purified organic phase, which was dried down in a vacuum centrifuge at $50^{\circ} \mathrm{C}$. The residue was resuspended in $50 \mu \mathrm{CHCl}_{3}$ and sampled for lipid analysis.

Phospholipids were analyzed by thin-layer chromatography (TLC) on heat-activated silica gel 60 plates (Merck, $20 \times 20 \mathrm{~cm}$ ) using one of the following solvent systems (ratios by vol.): (A) $\mathrm{CHCl}_{3} / \mathrm{MeOH} / \mathrm{NH}_{4} \mathrm{OH}(25 \%) / \mathrm{H}_{2} \mathrm{O}$ (90:70:4:16); or (B) ethylacetate/iso-octane/formic acid/ $\mathrm{H}_{2} \mathrm{O}$ (13:2:3:10), of which the organic phase was used for TLC. Solvent A was used for total phospholipid analysis, while B was used to quantitate $\mathrm{PtdOH}$ and PtdBut. Radiolabeled phospholipids were visualized and quantified by phosphoimaging (Molecular Dynamics, Sunnyvale CA, USA).

\section{RESULTS}

\section{COLD STRESS RAPIDLY TRIGGERS A PtdOH RESPONSE}

PtdOH levels in plants are approximately $2 \mathrm{~mol} \%$ of total phospholipids (Welti et al., 2002) which likely represents ER- and plastid-localized PtdOH as precursor and turnover product of structural glycerolipids. To be able to see PtdOH increases during stress-signaling, plants can be metabolically radiolabeled with carrier-free ${ }^{32} \mathrm{P}$-phosphate $\left({ }^{32} \mathrm{P}_{\mathrm{i}}\right)$. To study phospholipid metabolism during cold shock in Arabidopsis, we radiolabeled 5-days-old seedlings for $16 \mathrm{~h}$ with ${ }^{32} \mathrm{P}_{\mathrm{i}}$ and subsequently incubated them for $5 \mathrm{~min}$ at $0^{\circ} \mathrm{C}$. Phospholipids were then extracted, separated by TLC and analyzed by autoradiography. A typical ${ }^{32} \mathrm{P}-$ labeling pattern is shown in Figure 1, revealing a $\mathrm{PtdOH}$ increase in response to cold.

To test the temperature dependency of this response, ${ }^{32} \mathrm{P}_{\mathrm{i}}$-prelabeled seedlings were exposed to different temperatures for $5 \mathrm{~min}$. As shown in Figures 2A,B, a temperaturedependent $\mathrm{PtdOH}$ response was found. Concomitantly, a decrease in ${ }^{32} \mathrm{P}$-PtdInsP was observed (Figure 2A). To investigate whether leaves of adult plants responded similarly, leaf disks of 3 -weeks-old plants were subjected to the same labeling procedure and temperature treatments. Quantitation of the $\mathrm{PtdOH}$ levels by phosphoimaging revealed a significant response at $8^{\circ} \mathrm{C}$ or lower (Figure 2C), which is different for seedlings which already responded to a shift to $16^{\circ} \mathrm{C}$ (Figure 2B).

Next, the kinetics of the PtdOH response was investigated. As shown in Figure 3A, PtdOH accumulation at $0^{\circ} \mathrm{C}$ in seedlings reached a maximum within $2 \mathrm{~min}$ and then leveled off, staying up for at least $2 \mathrm{~h}$. The response of leaf disks of adult plants to $0^{\circ} \mathrm{C}$ was found to be slightly slower but was still relatively fast, peaking

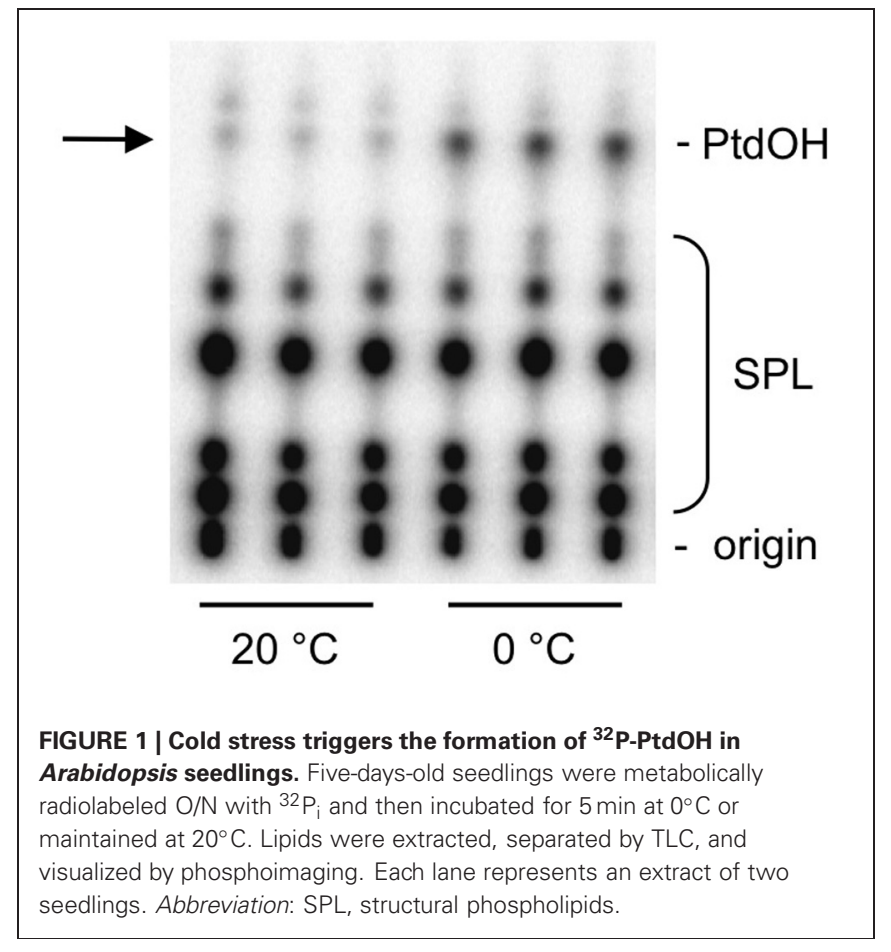

at $5 \mathrm{~min}$ after the onset of incubation after which it leveled off, approaching control levels after $2 \mathrm{~h}$ (Figure 3B).

\section{THE RAPID COLD INDUCED-PtdOH RESPONSE IS GENERATED BY DGK, NOT BY PLD ACTIVITY}

Next, we focused on the metabolic origin of the cold-induced $\mathrm{PtdOH}$ response. Previous studies in suspension-cultured Arabidopsis cells indicated that part of the cold shock-induced $\mathrm{PtdOH}$ response was generated by PLD activity (Ruelland et al., 2002). To investigate PLD's contribution a transphosphatidylation assay was performed, i.e., in the presence of a low concentration of a primary alcohol, such as n-ButOH, this serves as a substrate in a PLD-catalyzed reaction generating PtdBut, at the cost of PLD-catalyzed production of PtdOH (Munnik et al., 1995). The accumulation of PtdBut is a measure of PLD activity.

Thus, seedlings were prelabeled for $16 \mathrm{~h}$ with ${ }^{32} \mathrm{P}_{\mathrm{i}}$, then $\mathrm{n}$ $\mathrm{ButOH}(0.5 \%$ final conc.) was added, and $30 \mathrm{~min}$ later the seedlings were transferred to $0^{\circ} \mathrm{C}$ for $5 \mathrm{~min}$ or kept at room temperature. As shown in Figure 4A, cold stress did not affect ${ }^{32} \mathrm{P}$-PtdBut levels, while ${ }^{32} \mathrm{P}-\mathrm{PtdOH}$ levels increased. These data indicate that PLD is not responsible for the initial $\mathrm{PtdOH}$ response.

To investigate the potential involvement of DGK, a differential radiolabeling protocol was applied (Munnik, 2001; Arisz et al., 2009). In short, when cells are metabolically labeled with ${ }^{32} \mathrm{P}_{\mathrm{i}}$, the phospholipid classes are labeled with different kinetics, depending on the labeling of their precursors, their rates of synthesis, turnover, and pool size. Thus, DGK-derived PtdOH is labeled after relatively short labeling times because it acquires its ${ }^{32} \mathrm{P}$-phosphate directly from ATP molecules, which are rapidly labeled. This is in contrast to PtdOH arising from PLD activity, which are not labeled until the pool of its precursor, i.e., PtdEtn, 


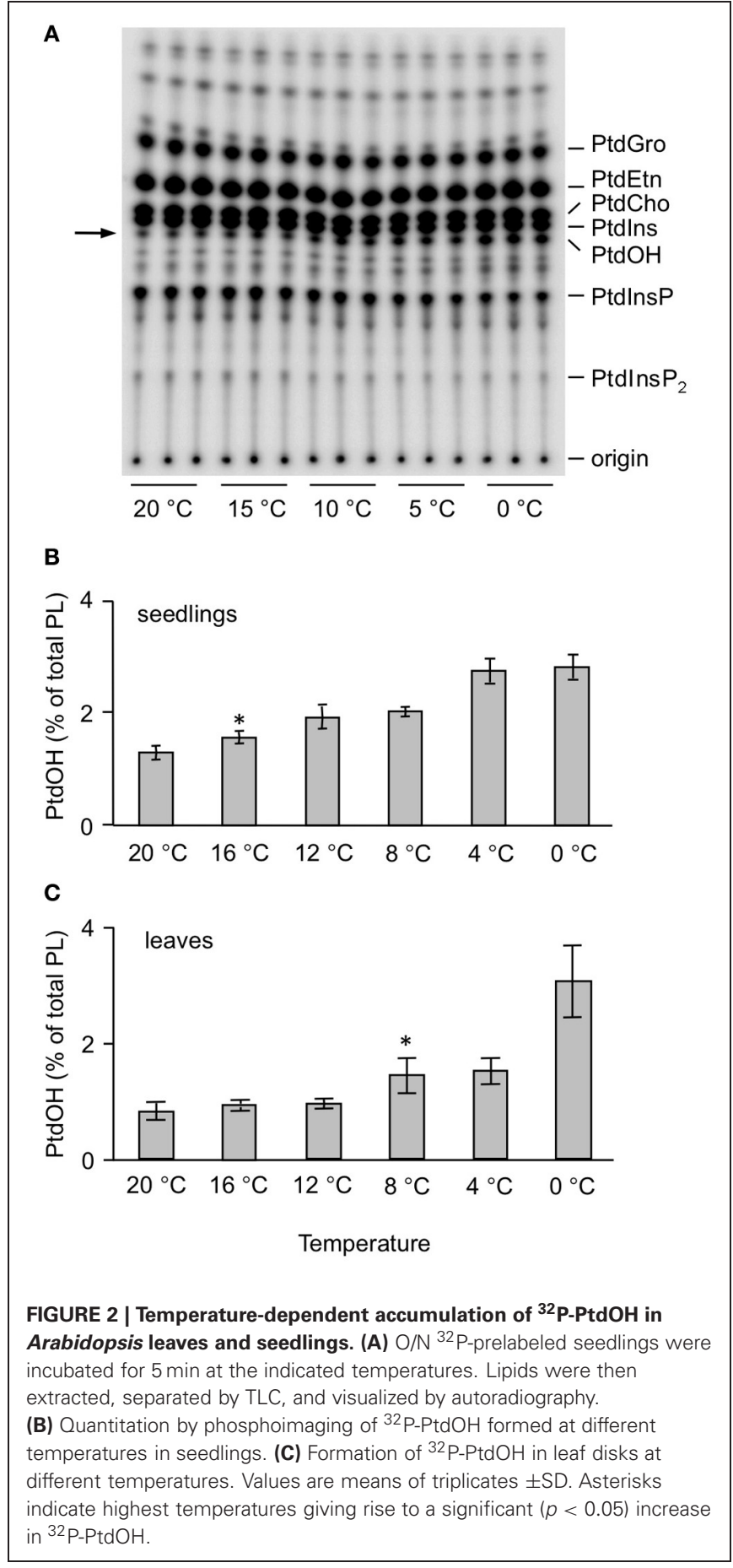

PtdCho, or PtdGro, is sufficiently labeled, which is typically $\mathrm{O} / \mathrm{N}$ (Munnik et al., 1998b; Arisz and Munnik, 2011).

Thus, seedlings were ${ }^{32} \mathrm{P}_{\mathrm{i}}$-prelabeled for different periods of time $(20,60$, and $180 \mathrm{~min})$ after which they were subjected for $5 \mathrm{~min}$ to $0^{\circ} \mathrm{C}$. As shown in Figures 4B,C, cold stress triggered a marked increase in ${ }^{32} \mathrm{P}-\mathrm{PtdOH}$ in seedlings prelabeled for only $20 \mathrm{~min}$. Under these conditions, structural phospholipids like PC and PE were hardly labeled excluding them as precursors to ${ }^{32} \mathrm{P}-\mathrm{PtdOH}$ in a $\mathrm{PLD}$-catalyzed reaction. This is in

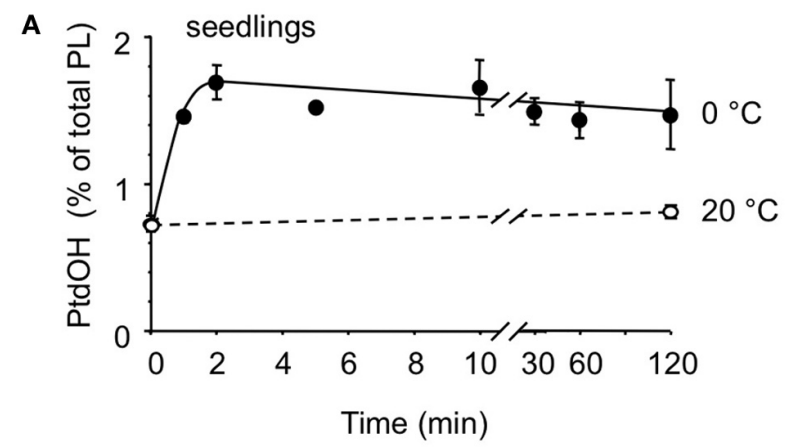

B

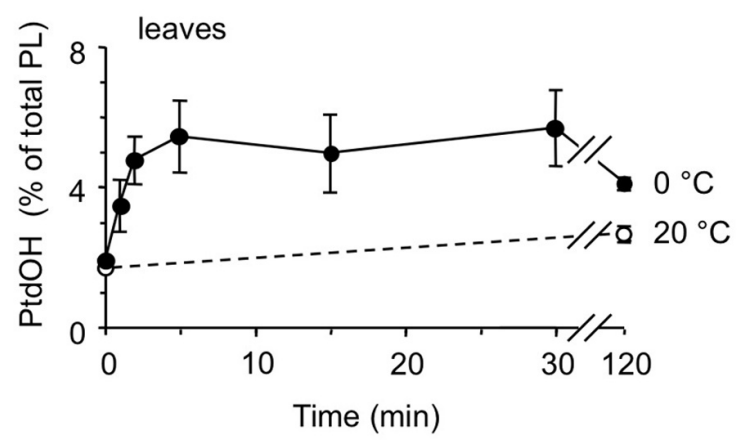

FIGURE 3 | Kinetics of cold-induced ${ }^{32} \mathrm{P}$-PtdOH accumulation in Arabidopsis seedlings and leaves. ${ }^{32} \mathrm{P}$-prelabeled seedlings (A) or leaf disks (B) were incubated at $0^{\circ} \mathrm{C}$ (filled circles) or $20^{\circ} \mathrm{C}$ (control, open circles) for different periods of time. Lipids were then extracted, separated by TLC, and quantified by phosphoimaging. Data points $( \pm S D)$ are from triplicate incubations.

agreement with the results of the transphosphatidylation assay (Figure 4A). Hence, the increase in ${ }^{32} \mathrm{P}-\mathrm{PtdOH}$ is unlikely to reflect a PLD activity, and is consistent with a DGK activity. At longer prelabeling time points, the relative increases in ${ }^{32} \mathrm{P}$ $\mathrm{PtdOH}$ gradually diminished (Figure 4C), due to the decrease in the specific radioactivity of the ATP pool and the general increase in structural phospholipid labeling.

Two of the most abundant PLD isoforms in Arabidopsis, $P L D \alpha 1$ and $P L D \delta$, have been implicated in cold stress tolerance (Ruelland et al., 2002; Li et al., 2004; Rajashekar et al., 2006). To test their contribution to the early PtdOH response to cold stress, both single and double KO-mutants were analyzed (Bargmann et al., 2009a,b). As shown in Figure 4D, all mutants exhibited a normal PtdOH response upon cold stress.

Together, these results argue against the involvement of PLD in the acute cold-shock-induced $\mathrm{PtdOH}$ response and strongly point to a role for DGK.

The implication of DGK in the early COR raised the question of DAG's metabolic origin. One possible source of DAG is the induced PLC hydrolysis of the polyphosphoinositides, PtdInsP and/or PtdInsP $\mathrm{P}_{2}$, a well-defined plant stress response, which was supported by the observation that ${ }^{32} \mathrm{P}$-PtdInsP decreased in response to cold (Figure 2A). Moreover, this decrease correlated closely with an equivalent increase in ${ }^{32} \mathrm{P}-\mathrm{PtdOH}$, in a temperature- and time-dependent fashion (Figure 5). These results strongly argue for the scenario that cold stress activates 
A

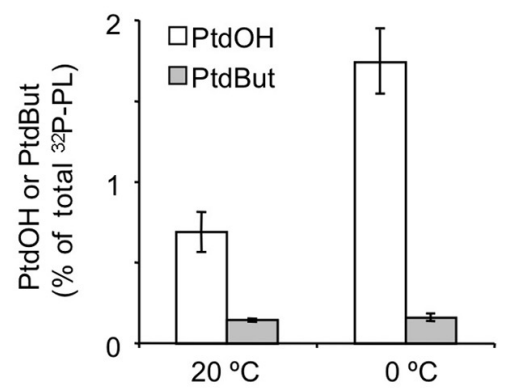

B

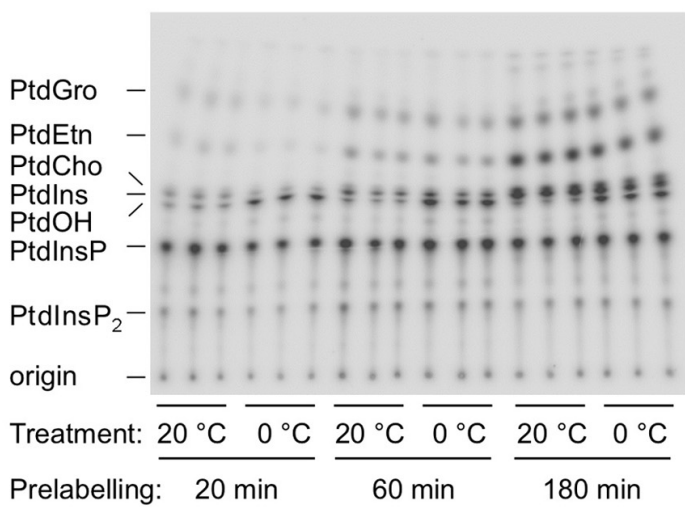

C

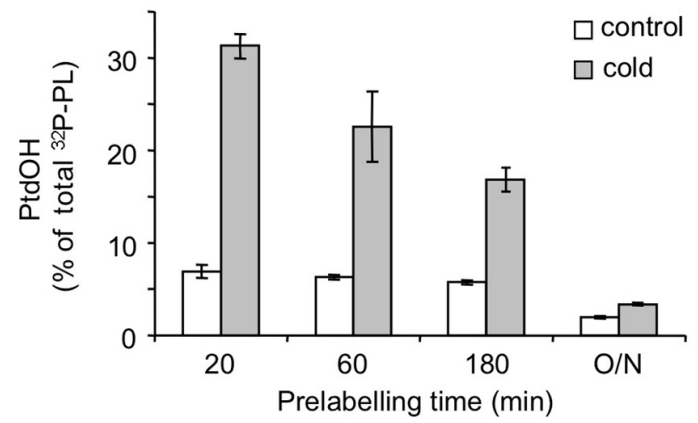

D

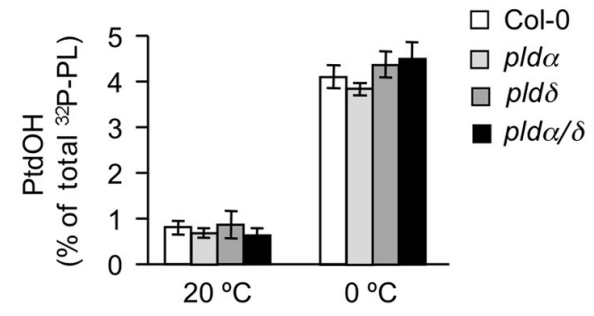

FIGURE 4 | Metabolic origin of the chilling-induced ${ }^{32} \mathrm{P}-\mathrm{PtdOH}$ response in Arabidopsis seedlings. (A) In the presence of 0.5\% $\mathrm{n}$-butanol, accumulation of the transphosphatidylation product ${ }^{32} \mathrm{P}$-PtdBut is used as measure of PLD activity. White bars, ${ }^{32} \mathrm{P}-\mathrm{PtdOH}$, gray bars,

${ }^{32} \mathrm{P}-\mathrm{PtdB}$ t. (B) Seedlings were prelabeled with ${ }^{32} \mathrm{P}$ for 20,60 , or $180 \mathrm{~min}$, to preferentially label the monoester-phosphates of lipids with high turnover rates. Subsequently, seedlings were transferred to cold $\left(0^{\circ} \mathrm{C}\right)$ or kept at $20^{\circ} \mathrm{C}$ for an additional $15 \mathrm{~min}$. Lipids were separated on TLC and visualized by phosphoimaging. (C) Dependence of ${ }^{32} \mathrm{P}-\mathrm{PtdOH}$ levels in control (white bars) and cold conditions (gray bars) on the ${ }^{32} \mathrm{P}$-prelabeling time. (D) Five-days old Col-0, plda1, pldd, and plda1/d knock-out seedlings were radiolabeled $\mathrm{O} / \mathrm{N}$ with ${ }^{32} \mathrm{Pi}$ and then incubated for $5 \mathrm{~min}$ at $0^{\circ} \mathrm{C}$ or maintained at $20^{\circ} \mathrm{C} .{ }^{32} \mathrm{P}-\mathrm{PtdOH}$ increases are expressed as percentage of total ${ }^{32}$-labeled lipids.

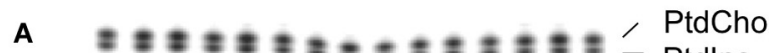 - Ptdlns PtdOH

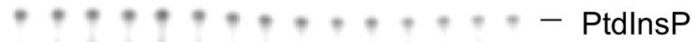 \\ $\overline{20{ }^{\circ} \mathrm{C}} \overline{15^{\circ} \mathrm{C}} \overline{10{ }^{\circ} \mathrm{C}} \overline{5^{\circ} \mathrm{C}} \overline{0^{\circ} \mathrm{C}}$ Temperature}

B

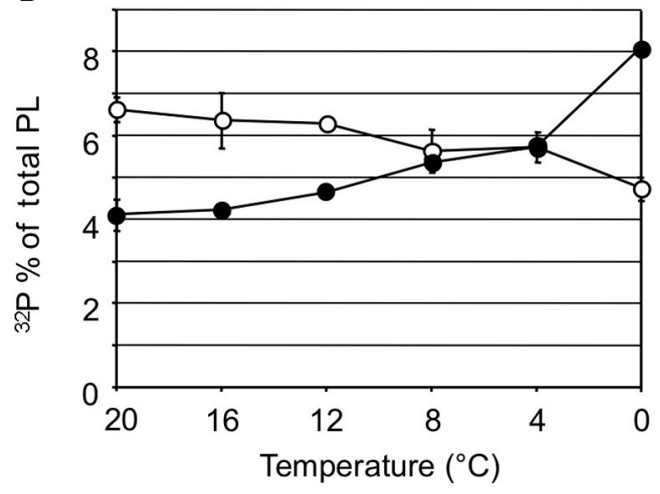

C

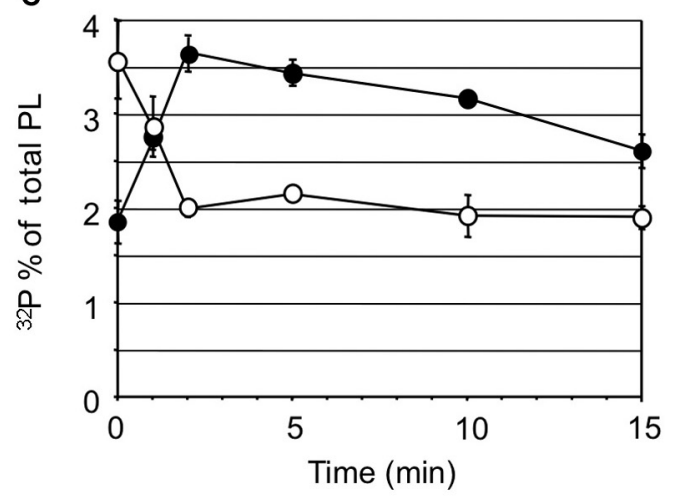

FIGURE 5 | Cold stress-induced changes in ${ }^{32} \mathrm{P}$-PtdOH vs. ${ }^{32} \mathrm{P}$-PtdlnsP. (A) TLC analysis of ${ }^{32} \mathrm{P}$-phospholipids extracted from seedlings after $5 \mathrm{~min}$ exposure to the temperatures indicated. (B) Similar experiment as (A) Quantitation of radioactivity in the lipids was by phosphoimaging. Filled circles, ${ }^{32} \mathrm{P}-\mathrm{PtdOH}$; open circles, ${ }^{32} \mathrm{P}-\mathrm{PtdlnsP}$ (C) A time course experiment at $0^{\circ} \mathrm{C}$ shows contrary changes in ${ }^{32} \mathrm{P}-\mathrm{PtdOH}$ and ${ }^{32} \mathrm{P}$-PtdlnsP. All values are means of at least three samples containing two seedlings each from a representative experiment (error bars indicate SD).

PLC hydrolysis of PtdInsP to form DAG, which is subsequently phosphorylated to PtdOH by DGK.

\section{PtdOH RESPONSES IN ARABIDOPSIS dgk- AND COLD STRESS MUTANTS}

Arabidopsis contains 7 DGK encoding genes. In an attempt to identify the isozyme involved in the cold-induced $\mathrm{PtdOH}$ response, a reversed genetic approach was used, screening a series of T-DNA insertion lines (Tables 1, 2). These lines carry insertions in or near the $D G K$ encoding regions, although not all of the lines were established as knockout or knockdown mutants (Table 1; Figure A4). Seedlings of these lines were 
Table 1 | Cold-induced PtdOH formation in seedlings of T-DNA insertion lines.

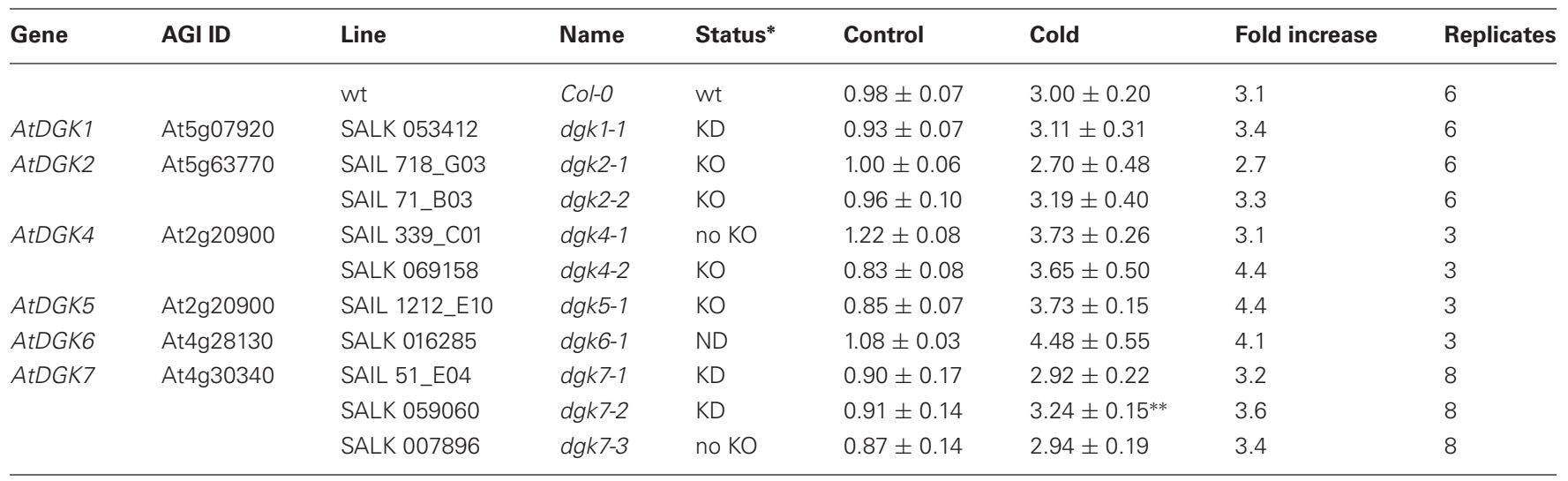

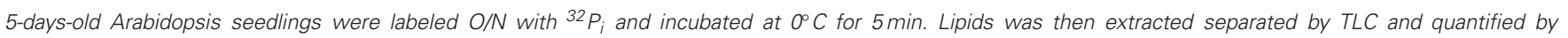
phosphoimaging. PtdOH levels are expressed as a percentage of the total ${ }^{32}$ P-labeled lipids and values represent averages of multiple samples containing 2 seedlings each $( \pm S D)$.

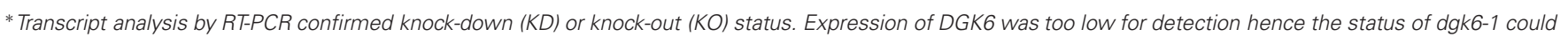
not be determined.

** Reproducible statistically significant difference of T-DNA line compared with wild type (Tukey HSD test, P $<0.05$ ) within the wild type control homogeneous subset.

Table 2 | Cold-induced PtdOH formation in leaf disks of T-DNA insertion lines.

\begin{tabular}{llll}
\hline & Control & Cold & Fold increase \\
\hline Col-0 & $2.1 \pm 0.7$ & $6.0 \pm 1.1$ & 2.9 \\
dgk1-1 & $2.2 \pm 0.5$ & $5.1 \pm 0.4$ & 2.3 \\
dgk2-1 & $2.2 \pm 0.6$ & $6.7 \pm 1.7$ & 3.1 \\
dgk2-2 & $1.9 \pm 0.3$ & $6.5 \pm 1.8$ & 3.3 \\
dgk4-1 & $1.9 \pm 0.4$ & $5.9 \pm 0.9$ & 3.2 \\
dgk4-2 & $2.0 \pm 0.3$ & $7.2 \pm 1.0$ & 3.7 \\
dgk5-1 & $3.3 \pm 0.3$ & $8.4 \pm 0.4$ & 2.6 \\
dgk6-1 & $2.6 \pm 0.2$ & $9.7 \pm 0.6^{*}$ & 3.7 \\
dgk7-1 & $2.0 \pm 0.4$ & $9.4 \pm 1.4^{*}$ & 4.6 \\
dgk7-2 & $2.3 \pm 0.5$ & $10.3 \pm 1.0^{* *}$ & 4.5 \\
dgk7-3 & $1.8 \pm 0.2$ & $8.7 \pm 0.5$ & 4.9 \\
\hline
\end{tabular}

Rosette leaf disks of 5-6-weeks-old Arabidopsis plants were labeled O/N with ${ }^{32} P_{i}$ and incubated at $0^{\circ} \mathrm{C}$ for 5 min. Lipids were extracted, separated by TLC and quantified by phosphoimaging. PtdOH levels are expressed as percentage of the total ${ }^{32}$ P-labeled lipids. Values are averages $\pm S D(n \geq 3)$.

${ }^{*, * *}$ Reproducible statistically significant difference of T-DNA line compared with wild type (Tukey HSD test, ${ }^{*} P<0.05 ; * *<0.01$ ) within the wild type control homogeneous subset.

${ }^{32} \mathrm{P}_{\mathrm{i}}$-prelabeled $(\mathrm{O} / \mathrm{N})$ and then exposed to $0^{\circ} \mathrm{C}$ for $5 \mathrm{~min}$ to measure their $\mathrm{PtdOH}$ response. Surprisingly, among the lines with normal control PtdOH levels, neither showed significant defects in the cold-induction of $\mathrm{PtdOH}$, whilst slight larger $\mathrm{PtdOH}$ increases were found in cold-stressed $d g k 7-2$ seedlings (Table 1). In leaf discs, $d g k 6-1, d g k 7-1$, and $d g k 7-2$ revealed slightly enhanced levels of cold-induced PtdOH (Table 2). Clearly, redundancy is involved and some of the $\mathrm{KO} / \mathrm{KD}$ lines may constitutively upregulate genes that even mask or enhance the response.
In Arabidopsis, several COR mutants have been identified, including ice1, snow1, fry1, hos1, and los1 [(Ishitani et al., 1998; Xiong et al., 2001; Guo et al., 2002; Chinnusamy et al., 2003) mutation has been demonstrated to negatively affect cold-induced gene transcription by interfering with the function of AtICE1, a myc-type transcription factor which functions in CBF transcription in cold signaling. The myb-type transcription factor SNOW1/MYB15, also binds to the CBF promoter region, interacting with ICE1 (Agarwal et al., 2006)]. To gain information on the position of the $\mathrm{PtdOH}$ response in the cold sensing pathway, each mutant was analyzed for its cold-induced PtdOH response. As shown in Figure 6A, fryl, hos1, and los1 all showed a normal response, but snow1 had a lower basal and cold shock-induced level of ${ }^{32} \mathrm{P}-\mathrm{PtdOH}(p=$ 0.006; Figure 6B); nevertheless, the relative stimulation levels were not significantly altered. Although the cold-induced $\mathrm{PtdOH}$ response in icel generally appeared to be lower than wildtype (Figure 7), it did not reach the significance level and was not cold-specific either, because the $\mathrm{PtdOH}$ response induced by salt stress $(300 \mathrm{mM} \mathrm{NaCl}, 15 \mathrm{~min}$ ) was also decreased ( $p=$ 0.008 ). Since these seedlings look stunted, pleiotropic effects are most likely to account for the observed differences. Similarly, PtdOH levels in the overexpressor of ICE1, Super-ICE1, tended to be suppressed, again indicating pleiotropic effects (Figure 7). Together these results indicate that the $\mathrm{PtdOH}$ response is upstream.

\section{DISCUSSION}

While, in Arabidopsis seedlings and leaves, the acclimation process in response to low temperatures is rapidly initiated, it takes 6-7 days to achieve maximal freezing tolerance (Uemura et al., 1995; Peng et al., 2007). The formation of PtdOH has been speculated to function in the regulation of this response (Ruelland et al., 2002; Xiong et al., 2002; Gomez-Merino et al., 2004; Li et al., 


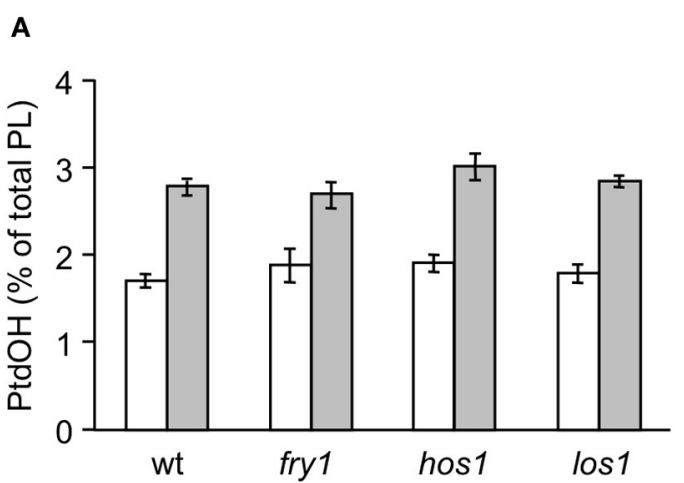

B

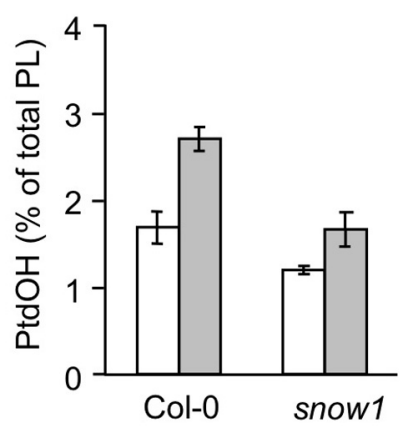

FIGURE 6 | Cold-induced ${ }^{32} \mathrm{P}$-PtdOH induction in known Arabidopsis cold response mutants. Five-days-old seedlings were prelabeled $\mathrm{O} / \mathrm{N}$ with ${ }^{32} \mathrm{P}$ and subsequently incubated at $0^{\circ} \mathrm{C}$ or kept at room temperature for $15 \mathrm{~min}$. Lipids were then extracted, separated by TLC, and quantified by phosphoimaging. ${ }^{32} \mathrm{P}-\mathrm{PtdOH}$ levels are expressed as percentage of the total ${ }^{32} \mathrm{P}$-lipid. Values are means from triplicate incubations from a typical experiment; error bars indicate SD. White bars, control; gray bars, $0^{\circ} \mathrm{C}$.

(A) The mutants fry1, hos1, los1, and their wt background,

C24RD29A-LUC. (B) The snow1 mutant and the wt control, Col-0.

2004; Vergnolle et al., 2005; Rajashekar et al., 2006). While this has previously been studied in suspension-cultured cells, we have focused on the response in whole seedlings and mature leaves. The results showed that cold shock treatment triggered a rapid and sustained (during hours) accumulation of $\mathrm{PtdOH}$, both in seedlings and in leaf discs of mature Arabidopsis plants (Figures 1-3). The leaf response was generally more pronounced, but in seedlings the PtdOH increase was faster and already visible upon minor temperature shifts which did not lead to a response in leaves. Since the accumulation of $\mathrm{PtdOH}$ is emerging as a common early element in environmental stress responses, and because it is suggested to be involved in the acclimation process, it is important to have knowledge of the underlying mechanisms.

\section{DGK RATHER THAN PLD ACTIVITY GENERATES EARLY, COLD-INDUCED PtdOH}

Two routes have been found to generate PtdOH under conditions of environmental stress in plants, i.e., PLD hydrolysis of strucural phospholipids (i.e., PtdCho/PtdEtn/PtdGro) and phosphorylation of DAG by DGK (Arisz et al., 2009; Testerink and Munnik,

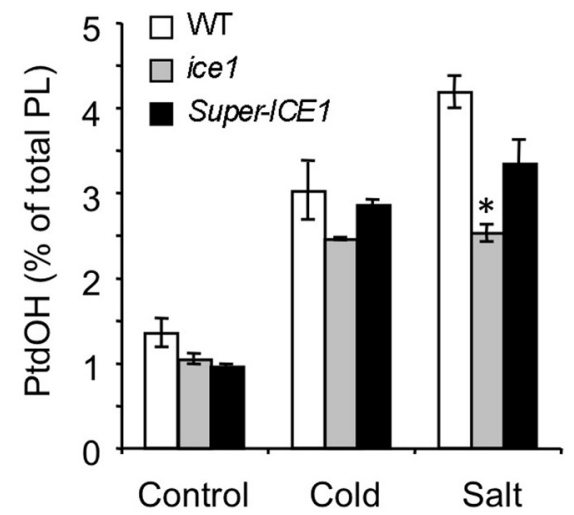

FIGURE $\left.7\right|^{32}$ P-PtdOH responses in seedlings of the ice 1 mutant and ICE1 overexpression transgenic line (Super-ICE1). Five-days-old seedlings were prelabeled $\mathrm{O} / \mathrm{N}$ with ${ }^{32} \mathrm{P}_{\mathrm{i}}$ and incubated at $0^{\circ} \mathrm{C}$ or with $300 \mathrm{mM} \mathrm{NaCl}$ for $15 \mathrm{~min} .{ }^{32} \mathrm{P}-\mathrm{PtdOH}$ levels are expressed as percentage of the total ${ }^{32} \mathrm{P}$-lipid (average $\pm \mathrm{SD}$ ). ${ }^{32} \mathrm{P}$ - $\mathrm{PtdOH}$ was enhanced due to cold and salt in all genotypes $(p<0.025)$, but salt-induced ${ }^{32} \mathrm{P}$-PtdOH was decreased in ice 1 compared to wildtype $\left({ }^{*} p=0.008\right)$.

2011). Using transphosphatidylation assays, the absence of a ${ }^{32} \mathrm{P}-\mathrm{PtdBut}$ increase under chilling conditions that triggered massive ${ }^{32} \mathrm{P}-\mathrm{PtdOH}$ responses indicate that $\mathrm{PLD}$ is not involved (Figure 4A). Using a differential ${ }^{32} \mathrm{P}_{\mathrm{i}}$-labeling assay, ${ }^{32} \mathrm{P}-\mathrm{PtdOH}$ demonstrated to be rapidly labeled, in agreement with a DGK involvement, and in contrast to the labeling of structural phospholipids PtdEtn, PtdCho, and PtdGro, which required long labeling times, again suggesting a PLD-independent pathway (Figure 4B).

Although this seemed at variance with studies of suspensioncultured cells, which suggested a cold-activated PLD activity (Ruelland et al., 2002; Cantrel et al., 2011), it is well-possible that PLD plays a role at a later phase of the COR. This is for example supported by (1) the induced membrane localization of PLD $\delta$ after 1 day at $2^{\circ} \mathrm{C}$ (Kawamura and Uemura, 2003), (2) its importance in freezing tolerance (Li et al., 2004; Chen et al., 2008; Du et al., 2010) and (3) the transcriptional regulation of Arabidopsis PLD $\delta$ and PLD $\alpha 1$ (Welti et al., 2002; Li et al., 2004) and two PLD $\alpha$ homologs from cotton (Kargiotidou et al., 2010) during cold acclimation. Nevertheless, consistent with the present data, we have found plda1/pld $\delta$ seedlings to display a normal ${ }^{32} \mathrm{P}-\mathrm{PtdOH}$ response after $5 \mathrm{~min}$ at $0^{\circ} \mathrm{C}$ (Figure 4D).

\section{THE SUBSTRATE FOR DGK MAY BE GENERATED BY A PtdINSP-HYDROLYZING PLC}

Since DGK was implicated, the question was raised how the substrate DAG was formed. Several pathways could account for this. A clue was provided by the concomitant decreases of ${ }^{32} \mathrm{P}$-PtdInsP, equivalent to the increase of ${ }^{32} \mathrm{P}-\mathrm{PtdOH}$, suggesting the former to be precursor to DAG and PtdOH via PLC and DGK, respectively (Figures 5 and $\mathbf{8}$, reactions 1 and 3 ). Previously, cold stress in Arabidopsis cells has been shown to trigger decreases in both PtdIns $\mathrm{P}_{2}$ and PtdInsP (Ruelland et al., 2002). While PdIns $\mathrm{P}_{2}$ is usually considered as the substrate for 
PLC, in plants PtdIns $\mathrm{P}_{2}$ levels are extremely low, and, in vitro, PtdInsP is hydrolyzed equally well (Cho et al., 1993; Munnik et al., 1998a; Munnik and Testerink, 2009; Munnik and Vermeer, 2009).

\section{PtdOH RESPONSE IN T-DNA INSERTION LINES}

To answer the question which of the seven DGK isozyme(s) in Arabidopsis was responsible for the cold shock-induced $\mathrm{PtdOH}$ response, we tested T-DNA insertion lines with insertions in or near the coding regions, which caused suppressed transcript levels in some but not all (Figures A3 and A4). Nonetheless, neither seedlings (Table 1), nor leaf discs (Table 2) carrying the insertion mutations displayed an abrogation of the $\mathrm{PtdOH}$ response. In contrast, in both systems a knock-down allele of DGK7, dgk72, was associated with an increased accumulation of $\mathrm{PtdOH}$. Knockdown of $D G K 2$, did not result in significantly reduced PtdOH levels, perhaps as a consequence of the activity of the structurally similar DGK1 (Gomez-Merino et al., 2004; Arisz et al., 2009).

These results may indicate a functional redundancy among Arabidopsis DGKs, such that deficient gene functions are compensated for by related isozymes. The PtdOH "overshoot" in the $d g k 7-2 \mathrm{KD}$ line could reflect such a mechanism. This experimental problem will be precluded by generating multigene KO lines, e.g., $d g k 1 / d g k 2$.

In young seedlings, but also in rosette leaves, $D G K 7$ is more abundantly expressed than DGK1 and DGK2 (Arisz et al., 2009), but its transcript levels have not been found to increase upon cold stress. Transgenically expressed DGK7 protein has been shown to have in vitro DGK activity despite the lack of a $\mathrm{C} 1$ domain, which is thought to function in the regulation of kinase activity in cluster-I DGKs, DGK1 and DGK2 (GomezMerino et al., 2004, 2005; Arisz et al., 2009). DGK7 belongs to cluster II, together with DGK3 and DGK4 whose activity may be responsible for the enhanced $\mathrm{PtdOH}$ production in $d g k 7-2$ seedlings.

\section{OTHER POTENTIAL SOURCES OF DAG AND PtdOH}

Although biochemical evidence strongly suggested a PLCDGK route, two alternative enzymes might be considered as contributors to the cold-induced $\mathrm{PtdOH}$ accumulation as well.

Inositolphosphorylceramide synthase (IPCS) transfers the inositol phosphate group from PtdIns to ceramide to generate inositolphosphorylceramide (IPC) and DAG (Figure A1). In yeast, the PtdIns substrate in this reaction is supplied through dephosphorylation of PtdIns4P by Sac1, coupling the consumption of PtdIns4P to the generation of DAG (Brice et al., 2009). An Arabidopsis IPCS, encoded by ERH1, has been implicated in pathogenic interactions (Wang et al., 2008). Interestingly, the physiological functions of PLC- and IPCS-mediated pathways may rely not only on the generation of inositol polyphosphates, IPC, and DAG/PtdOH, but also on the consumption of PtdInsP, which has novel functions in the biogenesis of secretory vesicles and the establishment/maintenance of cell polarity (reviewed by Munnik and Nielsen, 2011).
Recently, two interesting novel DAG sources have emerged in Arabidopsis stress responses: a PtdCho-hydrolyzing PLC, NPC4, that promotes tolerance to osmotic stresses (Peters et al., 2010), and SFR2, a galactolipid:galactolipid galactosyl transferase (GGGT), that produces DAG and oligogalactolipids to increase freezing tolerance (Thorlby et al., 2004; Moellering et al., 2010). For neither of the enzymes there is direct evidence that links their activity to stress-induced $\mathrm{PtdOH}$ accumulation. Rather, the enzymes could provide DAG as precursors for the synthesis of glycerolipids such as PtdCho and MGDG, or triacylglycerol, as for GGGT (Moellering et al., 2010; Moellering and Benning, 2011). It will nevertheless be interesting to subject $\mathrm{KO}$ mutants and overexpression lines of the corresponding genes to a differential PtdOH screen as we have applied in this study.

\section{PtdOH ACCUMULATION DUE TO COLD-INDUCED INHIBITION OF GLYCEROLIPID de novo SYNTHESIS?}

Cold may have a direct impact on glycerolipid de novo synthesis as it lowers diffusion rates and decreases the number of substrate molecules that have sufficient energy to allow enzymatic reactions (Mahan et al., 2004). In fact, in our differential labeling experiments we noticed a cold-induced decrease in the rate of PtdEtn labeling, only visible after approximately 20-30 min of labeling when its de novo synthesis in seedlings can just be witnessed (Figure 4B). Also in leaf discs, ${ }^{32} \mathrm{P}$-PtdEtn labeling was decreased upon cold incubation, suggesting a coldinduced inhibition of PE's de novo biosynthesis (Figure A2). This effect occurred at temperatures $\leq 8^{\circ} \mathrm{C}$, while the decrease remained constant at lower temperatures down to $0^{\circ} \mathrm{C}$. In contrast, maximum ${ }^{32} \mathrm{P}-\mathrm{PtdOH}$ accumulation was achieved at $0^{\circ} \mathrm{C}$ (Figure A2).

Glycerolipid de novo synthesis starts with two acylations of Gro3P to generate PtdOH (Figure 8). For the synthesis of PtdIns (and PtdGro), PtdOH is converted to cytidine diphosphatediacylglycerol (CDP-DAG), the substrate for phosphatidylinositol synthase (PIS). Alternatively, PtdOH is dephosphorylated by phosphatidic acid phosphatase (PAP) to generate DAG as substrate in a reaction by which phosphoethanolamine (EtnP) is transferred from cytidine diphosphate-ethanolamine (CDP-Etn) to the lipid moiety, yielding PtdEtn. Cold does not seem to cause a general inhibition in the uptake of ${ }^{32} \mathrm{P}_{\mathrm{i}}$ or its incorporation into the Kennedy pathway of glycerolipid de novo synthesis, since labeling of other structural phospholipids was not affected by cold stress (Figure A2). Therefore, the cause of decreased ${ }^{32} \mathrm{P}$-PtdEtn labeling is most likely in the synthesis or supply of its headgroup.

The precursor CDP-Etn is generated through the cytidylation of EtnP by phosphoethanolamine cytidylyl transferase (PECT), analogous to the PtdCho headgroup precursor CDP-Cho, being the product of phosphocholine cytidylyl transferase (CCT) using ChoP as substrate. The latter is produced by repeated methylations of EtnP, catalyzed by phosphoethanolaminemethyltranferase (PEAMT). This activity, which is considered rate-limiting for PtdCho synthesis, likely accounts for the different labeling kinetics of PtdCho and PtdEtn, only the latter being radioactively detected after $30 \mathrm{~min}$ of ${ }^{32} \mathrm{P}_{\mathrm{i}}$-labeling. 


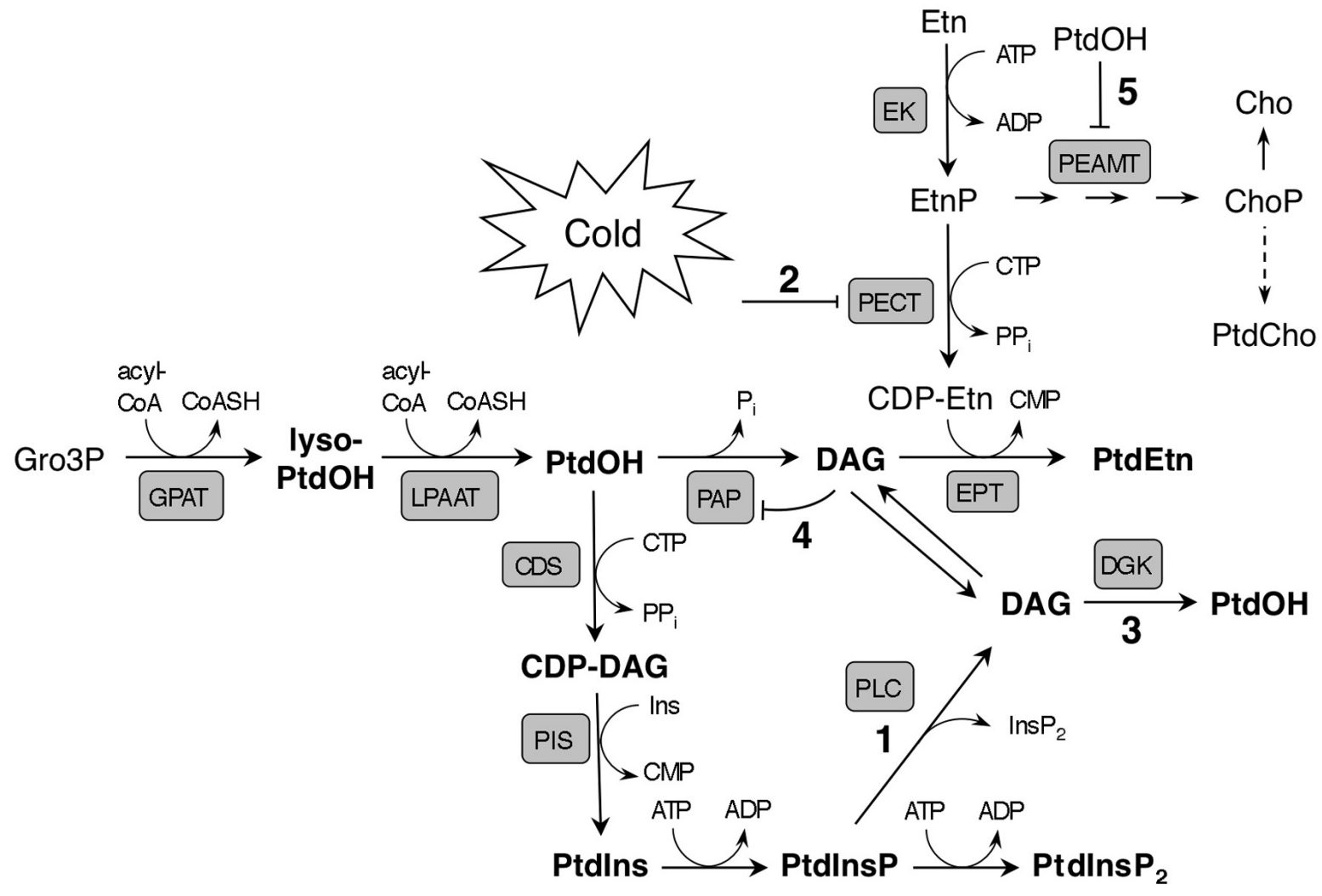

FIGURE 8 | Model illustrating potential early effects of cold stress on phospholipid metabolism and de novo synthesis in Arabidopsis. The main route to rapid cold-induced $\mathrm{PtdOH}$ formation is suggested to be based on the phosphorylation of PLC-generated DAG from PtdlnsP (reactions 1/3). The activity of PECT, which produces the precursor of the polar head of PtdEtn, CDP-Etn, is proposed to be down regulated by low ambient temperature (2). This would lead to reduced PtdEtn formation, and potentially, to DAG accumulation, which might cause $\mathrm{PtdOH}$ to accumulate as a result from phosphorylation of DAG by a DGK (3), or due to product inhibition of PAP by DAG (4). The major pathway of PtdCho synthesis depends on methylation of EtnP to ChoP by PEAMT, which could be inhibited by $\mathrm{PtdOH}$ (5). Note that the model only highlights immediate effects of cold temperature; longer exposure to cold induces a myriad of metabolic changes which impact lipid biosynthesis in different ways. Abbreviations: Acyl-CoA, acyl-coenzyme A; CDS, CDP-DAG synthase; EK, ethanolamine kinase; EPT, CDP-ethanolamine phosphotransferase; GPAT, glycerol 3-phosphate acyltransferase; LPAAT, Iysophosphatidic acid acyltransferase; lyso-PtdOH, lysophosphatidic acid.
As previous studies have shown that low temperatures can inhibit the in vitro activity of recombinant CCT (Inatsugi et al., 2002), PECT activity is speculated to be similarly downregulated by cold (Figure 8, designated by " 2 "), resulting in a limited availability of CDP-Etn for PtdEtn synthesis. This would form a bottleneck leading to the accumulation of DAG as precursor for PtdEtn synthesis. Notably, this DAG could be an additional source for cold-induced PtdOH through DGK activity (Figure 8, reaction 3), which has been shown to be partly localized at the ER in Arabidopsis (Vaultier et al., 2008). Alternatively, accumulated DAG may block its own formation through feedback inhibition of PtdOH phosphatase (Figure 8, reaction 4), again promoting $\mathrm{PtdOH}$ accumulation. Similar regulation of PAP activity by product inhibition has been demonstrated in chloroplast envelope membranes from spinach (Malherbe et al., 1992).

In summary, we have shown a very fast (in minutes) accumulation of $\mathrm{PtdOH}$ in response to cold temperatures in Arabidopsis seedlings and leaf discs, which was not due to PLD activity. Instead, ${ }^{32} \mathrm{P}$-radiolabeling studies indicated a dominant role of DGK under these conditions. Using single T-DNA insertion lines, we were unable to pinpoint the DGK gene(s) involved but do propose that DGK acts in tandem with a PtdInsP-hydrolyzing PLC, based on the close correlation between the increase in ${ }^{32} \mathrm{P}-\mathrm{PtdOH}$ and the decrease in ${ }^{32} \mathrm{P}$-PtdInsP.

PtdOH accumulation was not affected by the fryl, hos 1 , and los1 mutations, consistent with an independent, upstream position in cold signaling. Although the snow1 and ice 1 mutants displayed decreased PtdOH levels they likely reflected pleiotropic effects of the mutations.

Apart from the PLC/DGK route, additional, hypothetical sources of DAG and $\mathrm{PtdOH}$ were discussed, viz. via IPCS (Figure A1), NPC, GGGT and lipid de novo synthesis (Figure 8). Although for neither of these pathways there is sufficient evidence at present, they should not be ignored when studying PtdOH responses to cold or other environmental stresses. 


\section{REFERENCES}

Agarwal, M., Hao, Y., Kapoor, A., Dong, C. H., Fujii, H., Zheng, X., et al. (2006). A R2R3 type MYB transcription factor is involved in the cold regulation of CBF genes and in acquired freezing tolerance. J. Biol. Chem. 281, 37636-37645.

Arisz, S. A., and Munnik, T. (2011). The salt stress-induced LPA response in Chlamydomonas is produced via PLA hydrolysis of DGK-generated phosphatidic acid. J. Lipid Res. 52, 2012-2020.

Arisz, S. A., Testerink, C., and Munnik, T. (2009). Plant PA signaling via diacylglycerol kinase. Biochim. Biophys. Acta 1791, 869-875.

Bargmann, B. O. R., Arisz, S. A., Laxalt, A. M., ter Riet, B., van Schooten, B., Merquiol, E., et al. (2009a). Multiple PLDs required for high salinity- and water deficit tolerance in plants. Plant Cell Physiol. 50, 78-89.

Bargmann, B. O. R., Laxalt, A. M., ter Riet, B., Testerink, C., Merquiol, E., Mosblech, A., et al. (2009b). Reassessing the role of phospholipase D in the Arabidopsis wounding response. Plant Cell Environ. 32, 837-850.

Brice, S. E., Alford, C. W., and Cowart, L. A. (2009). Modulation of sphingolipid metabolism by the phosphatidylinositol-4-phosphate phosphatase Saclp through regulation of phosphatidylinositol in Saccharomyces cerevisiae. J. Biol. Chem. 284, 7588-7596.

Cantrel, C., Vazquez, T., Puyaubert, J., Reze, N., Lesch, M., Kaiser, W. M., et al. (2011). Nitric oxide participates in cold-responsive phosphosphingolipid formation and gene expression in Arabidopsis thaliana. New Phytol. 189, 415-427.

Carpaneto, A., Ivashikina, N., Levchenko, V., Krol, E., Jeworutzki, E., Zhu, J. K., et al. (2007). Cold transiently activates calciumpermeable channels in Arabidopsis mesophyll cells. Plant Physiol. 143, 487-494.

Chen, Q. F., Xiao, S., and Chye, M. L. (2008). Overexpression of the Arabidopsis 10-kilodalton acyl-coenzyme A-binding protein ACBP6 enhances freezing tolerance. Plant Physiol. 148, 304-315.

Chinnusamy, V., Ohta, M., Kanrar, S., Lee, B. H., Hong, X., Agarwal, M., et al. (2003). ICE1: a regulator of cold-induced transcriptome and freezing tolerance in Arabidopsis. Genes Dev. 17, 1043-1054.

Chinnusamy, V., Zhu, J., and Zhu, J. K. (2007). Cold stress regulation of gene expression in plants. Trends Plant Sci. 12, 444-451.
Cho, M. H., Shears, S. B., and Boss, W. F. (1993). Changes in phosphatidylinositol metabolism in response to hyperosmotic stress in Daucus carota L. cells grown in suspension culture. Plant Physiol. 103, 637-647.

Cook, D., Fowler, S., Fiehn, O., and Thomashow, M. F. (2004). A prominent role for the CBF cold response pathway in configuring the low-temperature metabolome of Arabidopsis. Proc. Natl. Acad. Sci. U.S.A. 101, 15243-15248.

Du, Z. Y., Xiao, S., Chen, Q. F., and Chye, M. L. (2010). Depletion of the membrane-associated acylcoenzyme A-binding protein ACBP1 enhances the ability of cold acclimation in Arabidopsis. Plant Physiol. 152, 1585-1597.

Gawer, M., Norberg, P., Chervin, D., Guern, N., Yaniv, Z., Mazliak, P., et al. (1999). Phosphoinositides and stress-induced changes in lipid metabolism of tobacco cells. Plant Sci. 141, 117-127.

Gomez-Merino, F. C., Arana-Ceballos, F. A., Trejo-Tellez, L. I., Skirycz, A., Brearley, C. A., Dormann, P., et al. (2005). Arabidopsis AtDGK7, the smallest member of plant diacylglycerol kinases (DGKs), displays unique biochemical features and saturates at low substrate concentration: the DGK inhibitor R59022 differentially affects AtDGK2 and AtDGK7 activity in vitro and alters plant growth and development. J. Biol. Chem. 280, 34888-34899.

Gomez-Merino, F. C., Brearley, C. A., Ornatowska, M., AbdelHaliem, M. E., Zanor, M. I., and Mueller-Roeber, B. (2004). AtDGK2, a novel diacylglycerol kinase from Arabidopsis thaliana, phosphorylates 1-stearoyl-2arachidonoyl-sn-glycerol and 1 , 2-dioleoyl-sn-glycerol and exhibits cold-inducible gene expression. J. Biol. Chem. 279, 8230-8241.

Guo, Y., Xiong, L., Ishitani, M., and Zhu, J. K. (2002). An Arabidopsis mutation in translation elongation factor 2 causes superinduction of CBF/DREB1 transcription factor genes but blocks the induction of their downstream targets under low temperatures. Proc. Natl. Acad. Sci. U.S.A. 99, 7786-7791.

Hirayama, T., Ohto, C., Mizoguchi, T., and Shinozaki, K. (1995). A gene encoding a phosphatidylinositolspecific phospholipase $\mathrm{C}$ is induced by dehydration and salt stress in Arabidopsis thaliana. Proc. Natl. Acad. Sci. U.S.A. 92, 3903-3907.

Hong, S. M., Bahn, S. C., Lyu, A., Jung, H. S., and Ahn, J. H. (2010).
Identification and testing of superior reference genes for a starting pool of transcript normalization in Arabidopsis. Plant Cell Physiol. 51, 1694-1706.

Inatsugi, R., Nakamura, M. and Nishida, I. (2002). Phosphatidylcholine biosynthesis at low temperature: differential expression of CTP: phosphorylcholine cytidylyltransferase isogenes in Arabidopsis thaliana. Plant Cell Physiol. 43, 1342-1350.

Ishitani, M., Xiong, L., Lee, H., Stevenson, B., and Zhu, J. K. (1998). HOS1, a genetic locus involved in cold-responsive gene expression in arabidopsis. Plant Cell 10, 1151-1161.

Jonak, C., Kiegerl, S., Ligterink, W. Barker, P. J., Huskisson, N. S., and Hirt, H. (1996). Stress signaling in plants: a mitogen-activated protein kinase pathway is activated by cold and drought. Proc. Natl. Acad. Sci. U.S.A. 93, 11274-11279.

Kargiotidou, A., Kappas, I., Tsaftaris, A., Galanopoulou, D., and Farmaki, T. (2010). Cold acclimation and low temperature resistance in cotton: Gossypium hirsutum phospholipase Dalpha isoforms are differentially regulated by temperature and light. J. Exp. Bot. 61 2991-3002.

Kawamura, Y., and Uemura, M. (2003). Mass spectrometric approach for identifying putative plasma membrane proteins of Arabidopsis leaves associated with cold acclimation. Plant J. 36, 141-154.

Knight, H., and Knight, M. R. (2000) Imaging spatial and cellular characteristics of low temperature calcium signature after cold acclimation in Arabidopsis. J. Exp. Bot. 51, 1679-1686.

Knight, H., Trewavas, A. J., and Knight, M. R. (1996). Cold calcium signaling in Arabidopsis involves two cellular pools and a change in calcium signature after acclimation. Plant Cell 8, 489-503.

Lee, B. H., Henderson, D. A., and Zhu, J. K. (2005). The Arabidopsis cold-responsive transcriptome and its regulation by ICE1. Plant Cell 17 , 3155-3175.

Li, M., Hong, Y., and Wang, X. (2009). Phospholipase D- and phosphatidic acid-mediated signaling in plants. Biochim. Biophys. Acta 1791, 927-935.

Li, W., Li, M., Zhang, W., Welti, R. and Wang, X. (2004). The plasma membrane-bound phospholipase Ddelta enhances freezing tolerance in Arabidopsis thaliana. Nat. Biotechnol. 22, 427-433.
Mahan, J. R., Dotray, P. A., and Light, G. G. (2004). Thermal dependence of enzyme function and inhibition; implications for, herbicide efficacy and tolerance. Physiol. Plant. 120, 187-195.

Malherbe, A., Block, M. A., Joyard, J., and Douce, R. (1992). Feedback inhibition of phosphatidate phosphatase from spinach chloroplast envelope membranes by diacylglycerol. J. Biol. Chem. 267, 23546-23553.

Mizoguchi, T., Irie, K., Hirayama, T., Hayashida, N., YamaguchiShinozaki, K., Matsumoto, K., et al. (1996). A gene encoding a mitogenactivated protein kinase kinase kinase is induced simultaneously with genes for a mitogen-activated protein kinase and an S6 ribosomal protein kinase by touch, cold, and water stress in Arabidopsis thaliana. Proc. Natl. Acad. Sci. U.S.A. 93, 765-769.

Moellering, E. R., and Benning, C. (2011). Galactoglycerolipid metabolism under stress: a time for remodeling. Trends Plant Sci. 16, 98-107.

Moellering, E. R., Muthan, B., and Benning, C. (2010). Freezing tolerance in plants requires lipid remodeling at the outer chloroplast membrane. Science 330, 226-228.

Munnik, T. (2001). Phosphatidic acid: an emerging plant lipid second messenger. Trends Plant Sci. 6, 227-233.

Munnik, T., Arisz, S. A., De Vrije, T., and Musgrave, A. (1995). G protein activation stimulates phospholipase D signaling in plants. Plant Cell 7 2197-2210

Munnik, T., Irvine, R. F., and Musgrave, A. (1998a). Phospholipid signalling in plants. Biochim. Biophys. Acto 1389, 222-272.

Munnik, T., van Himbergen, J. A. J., Ter Riet, B., Braun, F.-J., Irvine, R. F., van den Ende, H., et al. (1998b). Detailed analysis of the turnover of polyphosphoinositides and phosphatidic acid upon activation of phospholipases $\mathrm{C}$ and $\mathrm{D}$ in Chlamydomonas cells treated with non-permeabilizing concentrations of mastoparan. Planta 207, 133-145.

Munnik, T., and Nielsen, E. (2011). Green light for polyphosphoinositide signals in plants. Curr. Opin Plant Biol. 14, 489-497.

Munnik, T., and Testerink, C. (2009). Plant phospholipid signaling: "in a nutshell.” J. Lipid Res. 50(Suppl.), S260-S265.

Munnik, T., and Vermeer, J. E. M. (2009). Osmotic stress-induced phosphoinositide and inositol 
phosphate signalling in plants. Plant Cell Environ. 33, 655-669.

Peng, Y., Lin, W., Cai, W., and Arora, R. (2007). Overexpression of a Panax ginseng tonoplast aquaporin alters salt tolerance, drought tolerance and cold acclimation ability in transgenic Arabidopsis plants. Planta 226, 729-740.

Peters, C., Li, M., Narasimhan, R., Roth, M., Welti, R., and Wang, X. (2010). Nonspecific phospholipase C NPC4 promotes responses to abscisic acid and tolerance to hyperosmotic stress in Arabidopsis. Plant Cell 22, 2642-2659.

Rajashekar, C. B., Zhou, H. E., Zhang, Y., Li, W., and Wang, X. (2006). Suppression of phospholipase Dalphal induces freezing tolerance in Arabidopsis: response of cold-responsive genes and osmolyte accumulation. J. Plant Physiol. 163, 916-926.

Ruelland, E., Cantrel, C., Gawer, M., Kader, J. C., and Zachowski, A. (2002). Activation of phospholipases $\mathrm{C}$ and $\mathrm{D}$ is an early response to a cold exposure in Arabidopsis suspension cells. Plant Physiol. 130, 999-1007.

Sui, Z., Niu, L., Yue, G., Yang, A., and Zhang, J. (2008). Cloning and expression analysis of some genes involved in the phosphoinositide and phospholipid signaling pathways from maize (Zea mays L.). Gene 426, 47-56.

Tasma, I. M., Brendel, V., Whitham, S. A., and Bhattacharyya, M. K.
(2008). Expression and evolution of the phosphoinositide-specific phospholipase C gene family in Arabidopsis thaliana. Plant Physiol. Biochem. 46, 627-637.

Teige, M., Scheikl, E., Eulgem, T., Doczi, R., Ichimura, K., Shinozaki, K., et al. (2004). The MKK2 pathway mediates cold and salt stress signaling in Arabidopsis. Mol. Cell 15, 141-152.

Testerink, C., and Munnik, T. (2005). Phosphatidic acid: a multifunctional stress signaling lipid in plants. Trends Plant Sci. 10, 368-375.

Testerink, C., and Munnik, T. (2011). Molecular, cellular and physiological responses to phosphatidic acid formation in plants. J. Exp. Bot. 62, 2349-2361.

Thomashow, M. F. (1999). PLANT COLD ACCLIMATION: freezing tolerance genes and regulatory mechanisms. Annu. Rev. Plant Physiol. Plant Mol. Biol. 50, 571-599.

Thorlby, G., Fourrier, N., and Warren, G. (2004). The SENSITIVE TO FREEZING2 gene, required for freezing tolerance in Arabidopsis thaliana, encodes a beta-glucosidase. Plant Cell 16, 2192-2203.

Uemura, M., Joseph, R. A., and Steponkus, P. L. (1995). Cold Acclimation of Arabidopsis thaliana (effect on plasma membrane lipid composition and freeze-induced lesions). Plant Physiol. 109, 15-30.
Van Buskirk, H. A., and Thomashow, M. F. (2006). Arabidopsis transcription factors regulating cold acclimation. Physiol. Plant. 126, 72-80.

Vaultier, M. N., Cantrel, C., Guerbette, F., Boutte, Y., Vergnolle, C., Cicek, D., et al. (2008). The hydrophobic segment of Arabidopsis thaliana cluster I diacylglycerol kinases is sufficient to target the proteins to cell membranes. FEBS Lett. 582, 1743-1748.

Vergnolle, C., Vaultier, M. N., Taconnat, L., Renou, J. P., Kader, J. C., Zachowski, A., et al. (2005). The cold-induced early activation of phospholipase C and D pathways determines the response of two distinct clusters of genes in Arabidopsis cell suspensions. Plant Physiol. 139, 1217-1233.

Wang, W., Yang, X., Tangchaiburana S., Ndeh, R., Markham, J. E., Tsegaye, Y., et al. (2008). An inositolphosphorylceramide synthase is involved in regulation of plant programmed cell death associated with defense in Arabidopsis. Plant Cell 20, 3163-3179.

Welti, R., Li, W., Li, M., Sang, Y. Biesiada, H., Zhou, H. E., et al. (2002). Profiling membrane lipids in plant stress responses. Role of phospholipase D alpha in freezing-induced lipid changes in Arabidopsis. J. Biol. Chem. 277, 31994-32002.

Xiong, L., Lee, B., Ishitani, M., Lee, H., Zhang, C., and Zhu, J. K.
(2001). FIERY1 encoding an inositol polyphosphate 1-phosphatase is a negative regulator of abscisic acid and stress signaling in Arabidopsis. Genes Dev. 15, 1971-1984.

Xiong, L., Schumaker, K. S., and Zhu, J. K. (2002). Cell signaling during cold, drought, and salt stress. Plant Cell 14(Suppl.), S165-S183.

Conflict of Interest Statement: The authors declare that the research was conducted in the absence of any commercial or financial relationships that could be construed as a potential conflict of interest.

Received: 09 December 2011; accepted: 01 January 2013; published online: 22 January 2013.

Citation: Arisz SA, van Wijk R, Roels W, Zhu J-K, Haring MA and Munnik $T$ (2013) Rapid phosphatidic acid accumulation in response to low temperature stress in Arabidopsis is generated through diacylglycerol kinase. Front. Plant Sci. 4:1. doi: 10.3389/fpls.2013.00001

This article was submitted to Frontiers in Plant Physiology, a specialty of Frontiers in Plant Science.

Copyright (c) 2013 Arisz, van Wijk, Roels, Zhu, Haring and Munnik. This is an open-access article distributed under the terms of the Creative Commons Attribution License, which permits use, distribution and reproduction in other forums, provided the original authors and source are credited and subject to any copyright notices concerning any thirdparty graphics etc. 


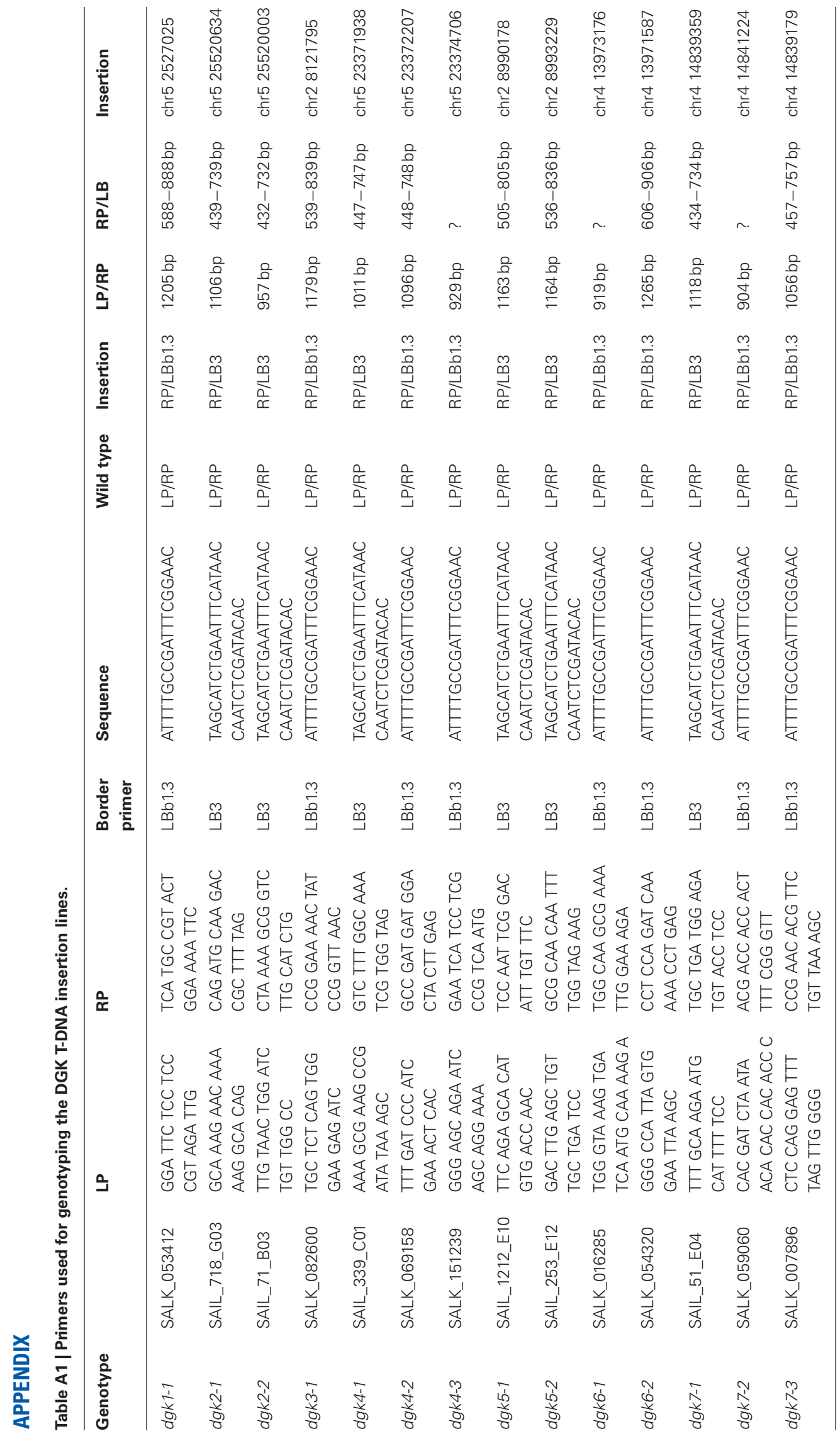


Table A2 | Primers used for RT-PCR expression analyses of DGK T-DNA insertion lines.

\begin{tabular}{|c|c|c|c|}
\hline Gene & Direction & Primername & Sequence \\
\hline & antisense & SALK_053412_RP & TCATGCCGTACTGGAAAATTC \\
\hline & antisense & dgk2 rv & GATCTACTCCACCCATATAGC \\
\hline \multirow[t]{2}{*}{$D G K 3$} & sense & SALK_082600_LP (dgk3-1) & TGCTCTCAGTGGGAAGAGATC \\
\hline & antisense & dgk3 rv & САААСТТСАТТССТСАСААСАС \\
\hline & antisense & dgk4 rv (A) & CCAAAGACTGGTGAGGGACTC \\
\hline & antisense & dgk4 r3 (B) & CGCATCTTTCCAGTCTCCTC \\
\hline \multirow[t]{2}{*}{ DGK5 } & sense & dgk5 fw2 & CCAGTGGCAGGACCTCCAC \\
\hline & antisense & dgk5 rv & GGAATCTTGAAGGTATCCGCAG \\
\hline$D G K 6$ & sense & dgk6 fw & CCTGGAACAGATAGGTCTTCG \\
\hline & antisense & At2g28390-Q-rv & GCTTTCTCTCAAGGGTTTCTGGGT \\
\hline
\end{tabular}

Sequences of the different primer pairs used to measure the expression of the various DGK genes used in this study. SAND (At2g28390) expression was used as the reference gene (Hong et al., 2010).

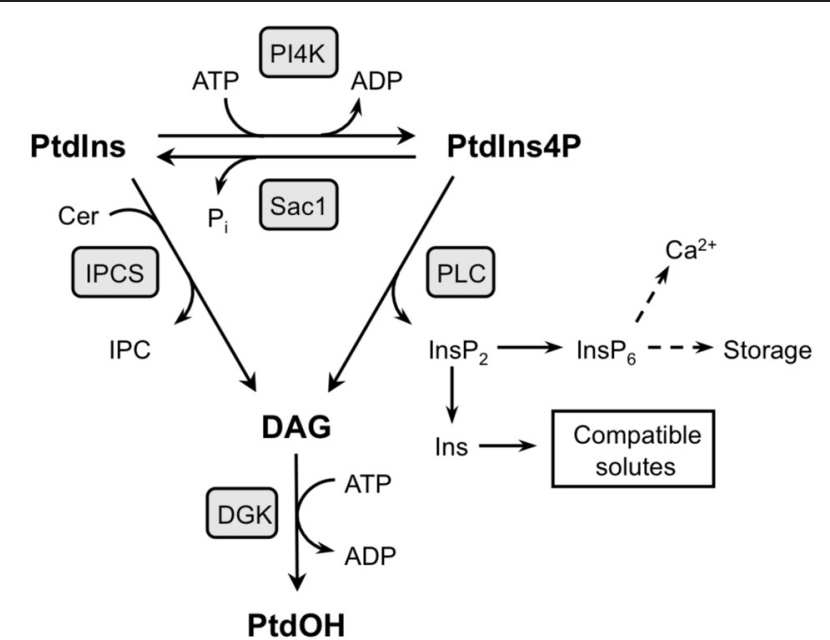

FIGURE A1 | Two pathways with the potential to generate DAG and PtdOH at the expense of Ptdlns4P. Ptdlns4P is suggested to be the substrate of cold-induced PLC activity which not only generates DAG, but at the same time releases $\operatorname{lns} P_{2}$ that can be converted to $\operatorname{lns}_{6}$ and/or Ins. The latter products may have a functional relevance in the stress response because $\mathrm{InSP}_{6}$ is a signaling compound in plants, and Ins is a precursor to compatible solutes (Vermeer and Munnik, 2010). Alternatively, inositolphosphorylceramide synthase (IPCS) generates DAG while transferring the InsP headgroup from Ptdlns to ceramide (Cer), generating inositolphosphorylceramide (IPC). The Ptdlns substrate in this conversion can be derived from Ptdlns4P dephosphorylation, as, in yeast, through Sac1 activity. DAG generated via either of these pathways may subsequently be phosphorylated by DGK to generate $\mathrm{PtdOH}$.

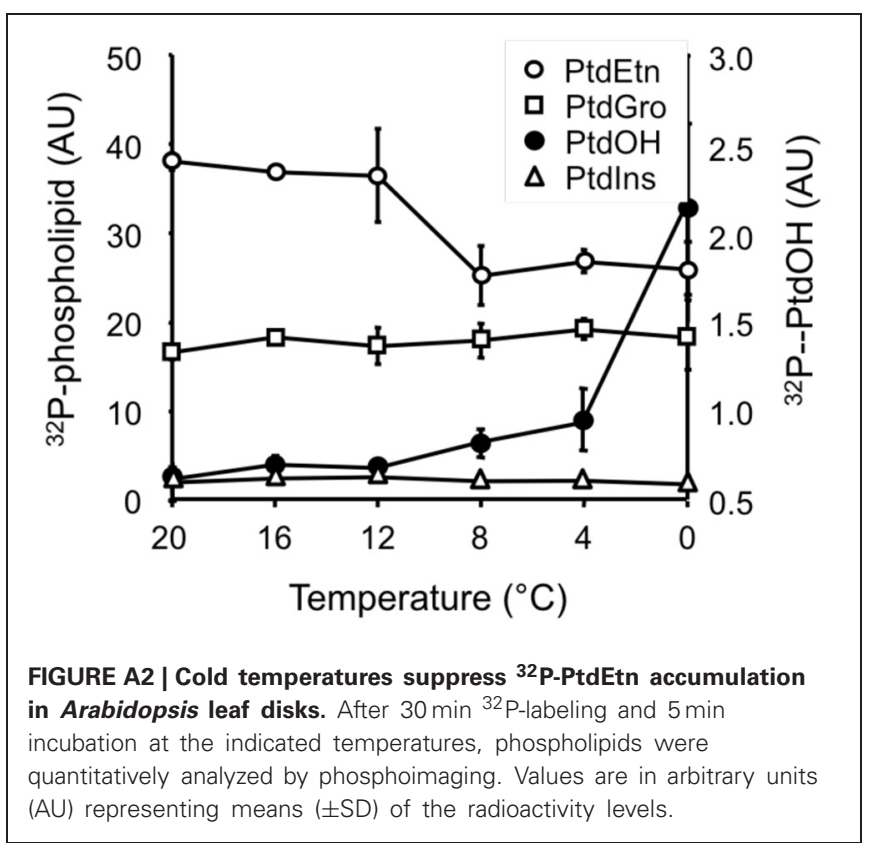




\section{dgk1-1}

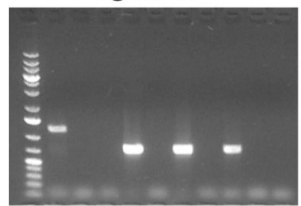

$d g k 2-1$

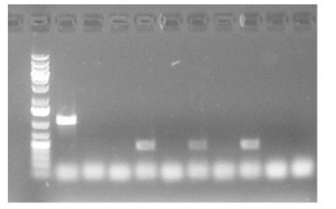

$d g k 2-2$

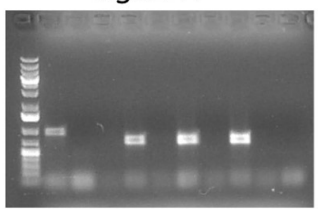

dgk3-1

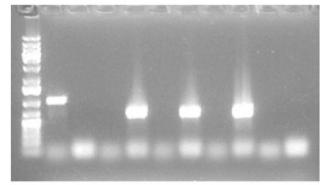

dgk4-1

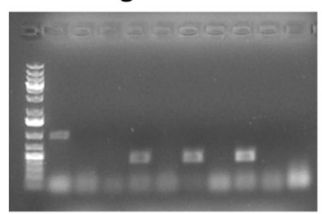

dgk4-2

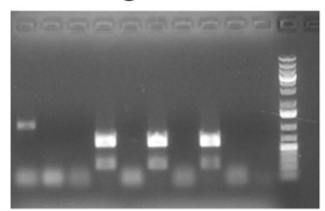

dgk4-3

dgk5-1

dgk5-2
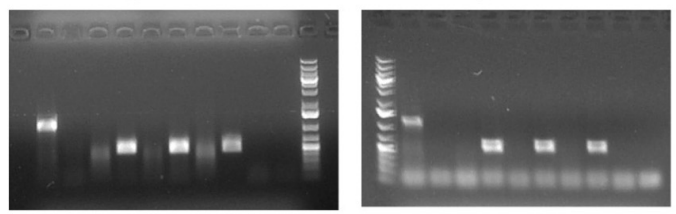

dgk6-1

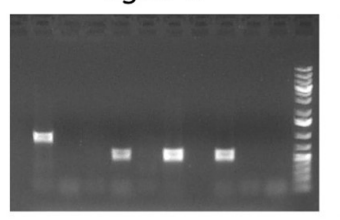

dgk6-2

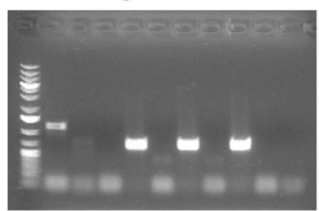

dgk7-1
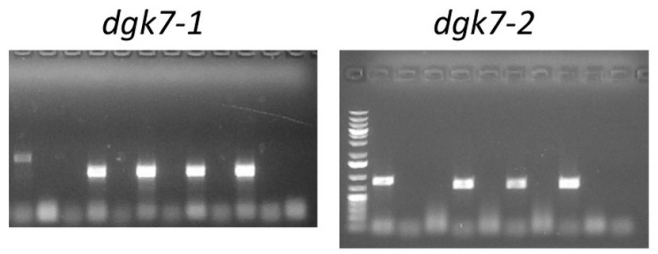

dgk7-3

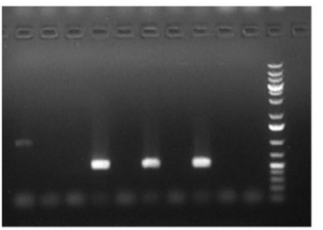

FIGURE A3 | Genotyping of the Arabidopsis dgk T-DNA insertion lines. DNA was isolated from leaf discs from 3 to 4 independent plants and zygosity determined by PCR using specific wt- and mutant-primer sets as listed in Table A1. Gel sample order (from left to right): Size marker; Col-0 $(w t)$, with first primer set, LP/RP (= wt band) and second primer set, RP/LB (= insertion band); Three (or four) independent dgk plants, with first primer set, LP/RP (= wt band) and second primer set RP/LB (= insertion band); Last lane, primer control (-). Some gels end with the size marker. Results clearly show that all lines used are homozygous T-DNA insertion lines since Col-0 was the only line giving wt bands and all insertion lines gave only bands with the second primer set. For the SALK lines LBb1.3 was used as LB primer, for the SAIL lines LB3 was used as LB primer (see primer list, Table A1). 

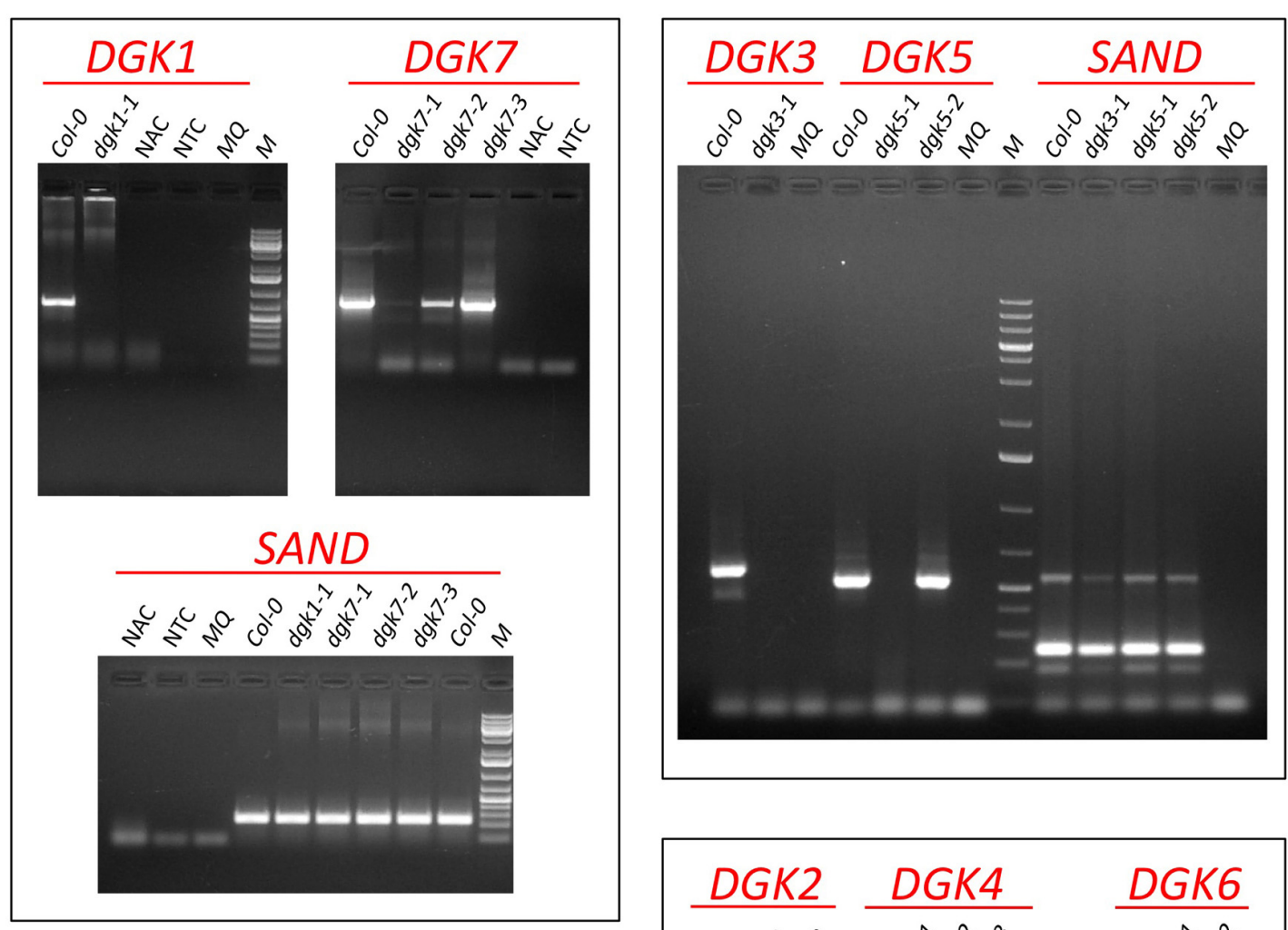

$$
\begin{aligned}
& \text { => Summary: } \\
& d g k 1-1 \text {-> KD (exon) } \\
& d g k 2-1 \text {-> KO (exon) } \\
& d g k 2-2 \text {-> KO (exon) } \\
& d g k 3-1 \text {-> KO/KD (3'UTR) } \\
& d g k 4-1->\text { no KD (3'UTR) } \\
& d g k 4-2->\text { KO (exon) } \\
& d g k 4-3->\text { no KD (promotor) } \\
& d g k 5-1 \text {-> KO/KD intron) } \\
& d g k 5-2 \text {-> no KD (intron 5'UTR) } \\
& \text { DGK6 - > ND } \\
& d g k 6-1 \text {-> possible KO/KD (exon) } \\
& d g k 6-2 \text {-> OE (exon, 40bp after ATG) } \\
& d g k 7-1 \text {-> strong KD (exon) } \\
& d g k 7-2 \text {-> weak KD (promotor) } \\
& d g k 7-3 \text {-> no KD (intron) }
\end{aligned}
$$

FIGURE A4 | Determination of DGK KO/KD-expression in Arabidopsis T-DNA insertion mutants by RT-PCR. RNA was isolated from 9-days old roots $(D G K 1,-3,-5,-7)$ or flowers $(D G K 2,-4,-6)$ since the latter genes did not reveal expression in the root (not shown). Predicted band Sizes: DGK1, 702 bp; DGK3, 592 bp; DGK5, 534 bp; DGK6, 434 bp;

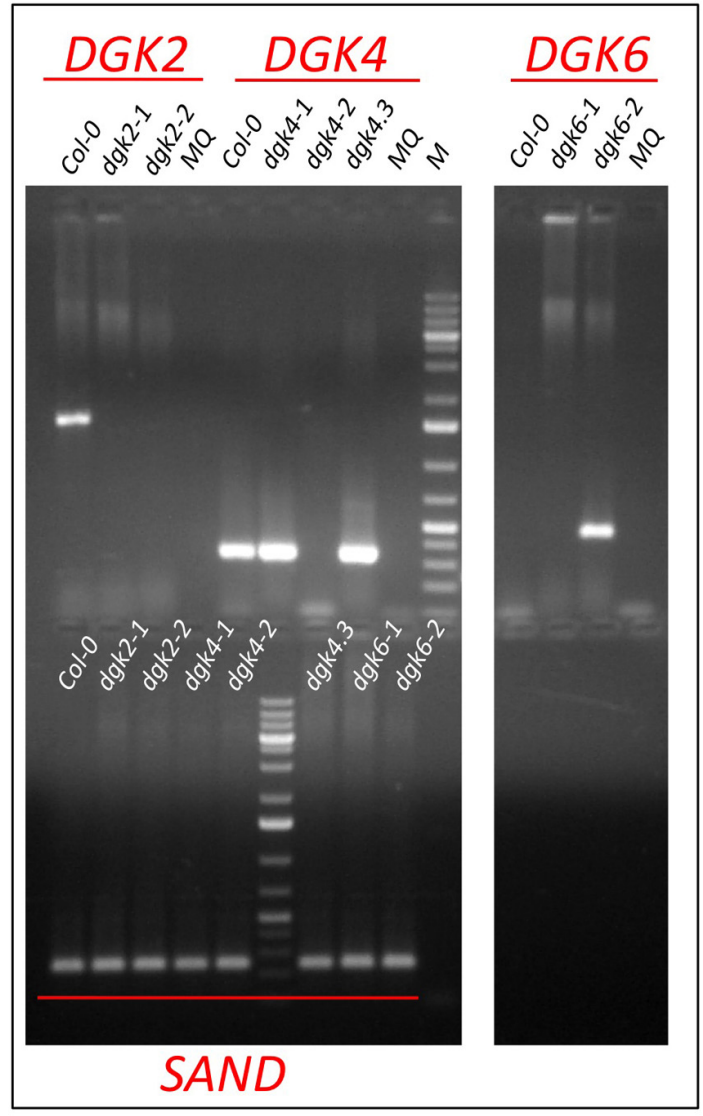

DGK7, 791 bp; SAND (reference gene), 244 bp. Abbreviations: ND, not detectable; NAC, non-amplification control (test for genomic DNA contamination), i.e., RT reaction without RT enzyme on Col-0 RNA; NTC, no target control (test for contamination + primer dimers), i.e., RT reaction with water sample. 